\title{
Effect of water temperature on protein requirement of Heteropneustes fossilis (Bloch) fry as determined by nutrient deposition, hemato-biochemical parameters and stress resistance response
}

Shabihul Fatma ${ }^{1 *}$ (i) and Imtiaz Ahmed ${ }^{2}$

\begin{abstract}
Background: Dietary protein requirements are dependent on a variety of factors and water temperature is one of the most important abiotic factors affecting protein requirement of fish. This study was, therefore, conducted to investigate effects of water temperature on dietary protein requirement of fry Heteropneustes fossilis which has high demand in most of the Asian markets.

Methods: Quadruplicate groups of 30 fish per treatment $(2.97 \pm 0.65 \mathrm{~cm} ; 5.11 \pm 0.34 \mathrm{~g})$ were fed seven isoenergetic diets $\left(17.9 \mathrm{k} \mathrm{g} \mathrm{g}^{-1}\right.$ gross energy; $14.99 \mathrm{~kJ} \mathrm{~g}^{-1}$ digestible energy) containing dietary protein levels ranging from 28 to $52 \%$ at two water temperatures $\left(18\right.$ and $\left.26^{\circ} \mathrm{C}\right)$. Experimental diets were fed to apparent satiation as semi-moist cakes thrice daily at 17:00, 12:00, and 17:30 h for 12 weeks. For precise information, various growth parameters, protein deposition, hematological parameters, metabolic enzymes, and stress response were analyzed, and effects of water temperature on dietary protein requirement was recommended on the basis of response from above parameters.

Results: Groups held at $26^{\circ} \mathrm{C}$ attained best growth, feed conversion, and protein deposition at $44 \%$ dietary protein indicating that temperature affected dietary protein requirement for optimum growth of $\mathrm{H}$. fossilis fry and protein requirement seems to be satisfied with $44 \%$ dietary protein. Interestingly, interactive effects of both dietary protein levels and temperature were not found $(P>0.05)$. Fish reared at $18^{\circ} \mathrm{C}$ had comparatively higher values for aspartate and alanine transferases than those reared at $26^{\circ} \mathrm{C}$ water temperature which exhibited normal physiological value for these enzymes indicating that body metabolism was normal at this temperature. Hematological parameters also followed same pattern. Furthermore, fish reared at $26{ }^{\circ} \mathrm{C}$ water temperature exhibited more resistant to thermal stress $(P<0.05)$. The $95 \%$ maximum plateau of protein deposition data using second-degree polynomial regression analyses exhibited dietary protein requirement of fry $\mathrm{H}$. fossilis between 40.8 and $41.8 \%$ of diet at $26^{\circ} \mathrm{C}$ water temperature. The recommended range of dietary protein level and protein/digestible energy ratio for fry $H$. fossilis is $40.8-41.8 \%$ and 27.21-27.88 $\mathrm{mg}$ protein $\mathrm{kJ}^{-1}$ digestible energy, respectively.
\end{abstract}

Conclusions: Information developed is of high significance for optimizing growth potential by making better utilization of nutrient at $26^{\circ} \mathrm{C}$ and, to develop effective management strategies for mass culture of this highly preferred fish species.

Keywords: Temperature, Heteropneustes fossilis, Growth, Metabolic enzymes, Hematological parameters

\footnotetext{
*Correspondence: ftm77@rediffmail.com; Ssaid@jazanu.edu.sa

'Department of Nursing, Farasan University College, Farasan, Jazan University,

Jizan, Kingdom of Saudi Arabia

Full list of author information is available at the end of the article
}

(c) The Author(s). 2020 Open Access This article is distributed under the terms of the Creative Commons Attribution 4.0 International License (http://creativecommons.org/licenses/by/4.0/), which permits unrestricted use, distribution, and reproduction in any medium, provided you give appropriate credit to the original author(s) and the source, provide a link to the Creative Commons license, and indicate if changes were made. The Creative Commons Public Domain Dedication waiver (http://creativecommons.org/publicdomain/zero/1.0/) applies to the data made available in this article, unless otherwise stated. 


\section{Introduction}

Protein assumes greater importance in aquacultural feeds mainly due to the fact that the level and quality of protein greatly influences feed cost. Therefore, protein content should be carefully adjusted in feeds, bearing in mind that the dietary protein in excess to that required for growth is only catabolized (Cowey 1979) and that protein inadequacy leads to poor growth and feed inefficiency. Consequently, to improve the utilization of protein for tissue synthesis rather than for energy purposes, an adequate knowledge of protein requirements and of the effect of environmental factors on protein utilization is necessary.

Dietary protein requirements are dependent on a variety of factors such as stock size, water temperature, feeding frequency, amount of non-protein dietary energy, and dietary protein quality (Shimeno et al. 1980). As fish is an ectotherm, and water temperature is one of the most important abiotic factors affecting growth and survival of the aquatic animals. All fish species are characterized by an ideal range of temperature in which they show their maximum growth (Oyugi et al. 2011). Any alterations in the optimum water temperature have a marked and direct effect on many of the key physiological processes and behavioral activities (Brett 1979; Jonassen et al. 2000; Sarma et al. 2010) which can also be detected in the form of alterations in hematological parameters (Haider 1973; Steinhagen et al. 1990). Temperature beyond optimum limits of a particular species adversely affects the health of aquatic animal due to metabolic stress and increases oxygen demand and susceptibility to diseases (Wedemeyer et al. 1999). It limits the biochemical reactions, affects their metabolism and distribution, and directly influences the survival and growth at the various stages of their life cycle.

Catfishes are the preferred candidate species for aquaculture owing to their consumer preference and commercial and medicinal value. Among those, Heteropneustes fossilis, commonly known as the stinging catfish or singhi, is considered as one of the most demanded freshwater air breathing fish species in the tropical waters of the Indian subcontinent and Southeast Asian region (Christopher et al. 2010). The range encompasses India, Thailand, Bangladesh, Pakistan, Nepal, Sri Lanka, Myanmar, Indonesia, and Cambodia (Burgess 1989). Its primary habitat includes ponds, ditches, swamps, and marshes. It is hardy, amenable to high stocking densities, and adapts well to hypoxic water bodies (Dehadrai et al. 1985). Due to the presence of accessory respiratory organs, it has got the ability to utilize atmospheric oxygen for respiration and, therefore, can survive for quite a few hours outside the water which makes it an ideal species for aquaculture (Vijayakumar et al. 1998; Haniffa and Sridhar 2002). Heteropneustes fossilis is an important tropical freshwater food fish (Mohamed and Ibrahim 2001). It has very high iron content $(226 \mathrm{mg} / 100 \mathrm{~g})$ and fairly high content of calcium compared to many other freshwater fishes (Saha and Guha 1939). Being a lean fish, it is very suitable for people to whom animal fats are undesirable (Rahman et al. 1982). Due to high nutritive value and low fat content, the stinging catfish is recommended in the diets of the sick and the convalescents (Alok et al. 1993). The fish efficiently utilizes prepared feeds and is able to withstand adverse environmental conditions. In addition to this, it has high nutritional and medicinal value (Pillay 1990; Jhingran 1991; Thakur 1991). This fish is popular particularly because it can be cultivated in swampy areas and derelict water bodies without involving costly reclamation. It is easily stored and transported live to consumers. Thus, this species is ideal for wastewater aquaculture as well (Tharakan and Joy 1996) and is abundantly available in open water system of floodplains, canals, and beels.

The effects of water temperature on growth and protein requirements of fish have been well documented for many species (El-Sayed et al. 1996; Van Ham et al. 2003; Anelli et al. 2004; Chatterjee et al. 2004; Larsson and Berglund 2005; Han et al. 2008; Singh et al. 2008; Singh et al. 2009; Huang et al. 2016; Mishra et al. 2019). Some aspects of nutrition of $H$. fossilis has been worked out in the past mainly on determining its optimum feeding practices and nutritional requirements (Niamat and Jafri 1984; Akand et al. 1991; Jhingran 1991; Anwar and Jafri 1992; Firdaus 1993; Firdaus et al. 1994; Firdaus and Jafri 1996; Mohamed 2001; Mohamed and Ibrahim 2001; Firdaus et al. 2002; Usmani and Jafri 2002; Usmani et al. 2003; Ahmed 2007; Siddiqui and Khan 2009; Ahmed 2010; Khan and Abidi 2010; Khan and Abidi 2011a, 2011b; Ahmed 2012; Farhat 2011; Farhat 2012; Khan and Abidi 2012; Ahmed 2013a, 2013b; Farhat 2013a, 2013b; Ahmed 2014; Farhat 2014a, 2014b, 2014c; Khan and Abidi 2014; Ahmed 2017; Farhat 2017); however, study on effect of water temperature on the nutritional requirements of $H$. fossilis under culture condition has not been worked out.

Since biochemical parameters such as serum aspartate amino transferase (AST) and alanine amino transferase (ALT) levels and the hematological parameters commonly measured clinically as biomarkers for health and good indicator of various sources of stress, to ascertain the effect of temperature on dietary protein requirement more precisely, these parameters are also considered and analyzed.

The aim of this study was to determine the influence of water temperature on protein requirement and to optimize the rearing temperature so that this fish could maximize its performance in terms of growth and health in an intensive culture system. 


\section{Materials and methods Experimental diets}

Seven casein-gelatin-based isocaloric diets $(14.99 \mathrm{~kJ} / \mathrm{g}$ digestible energy) with varying levels of dietary protein $(28,32,36,40,44,48,52 \%$ protein) were prepared (Table 1). Diets were designated as $\mathrm{D}_{28}, \mathrm{D}_{32}, \mathrm{D}_{36}, \mathrm{D}_{40}$, $\mathrm{D}_{44}, \mathrm{D}_{48}$, and $\mathrm{D}_{52}$. Two intact protein sources, casein and gelatin, were used at 4:1 ratio. The dietary protein level was increased by adjusting the fractions of casein and gelatin in the diet. Dextrin was served as the carbohydrate source. A combination of cod liver oil and corn oil (2:5) was used as a source of lipid to provide $n-3$ and n- 6 fatty acids. Vitamin and mineral premixes were prepared as per Halver (2002). Digestible energy (DE) was

Table 1 Composition of experimental diets

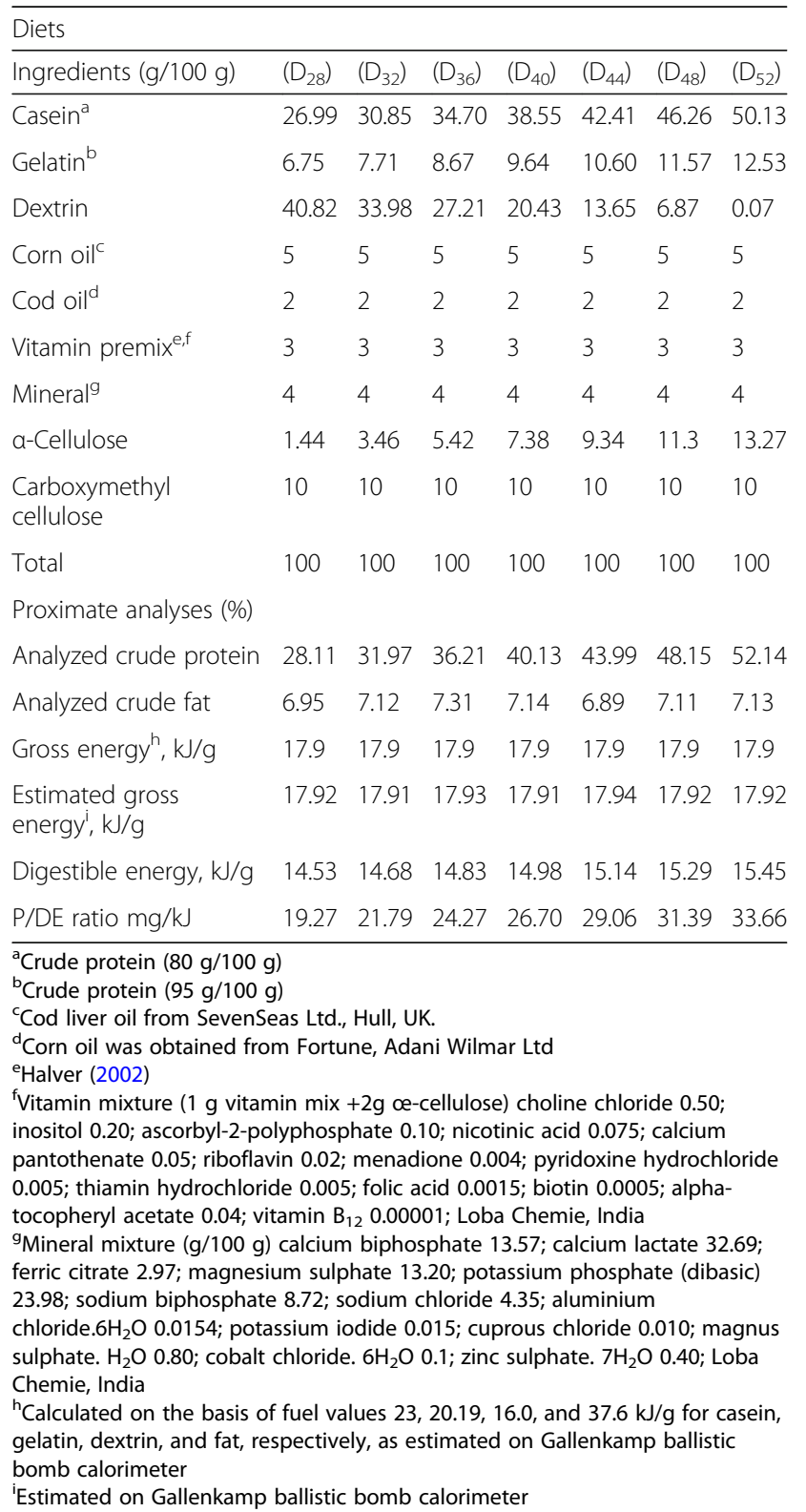

calculated using conversion factors of 33.5, 20.9, and $12.6 \mathrm{~kJ} / \mathrm{g}$ for fat, protein, and carbohydrate, respectively (Halver and Hardy 2002). The diet was prepared as per Siddiqui and Khan (2009). The final diet in the form of dough was cut into small cubes, sealed in polythene bags, and kept in refrigerator at $-20{ }^{\circ} \mathrm{C}$ till further use.

\section{Experimental design and feeding trial}

Induced-bred fry of the stinging catfish, $H$. fossilis, were obtained from the Ghazipur Fish Market, New Delhi, India and transported to wet laboratory (Fish Rearing Laboratory, Department of Zoology, Central University of Kashmir, J\&K), given a prophylactic dip in $\mathrm{KMnO}_{4}$ solution (1:3000) and stocked in indoor circular aquablue colored, plastic lined (Plastic Crafts Corp, Mumbai, India) fish tanks $(1.22 \mathrm{~m} \times 0.91 \mathrm{~m} \times 0.91 \mathrm{~m}$; water volume $600 \mathrm{~L}$ ) for about 2 weeks. They were then acclimated to two different constant temperatures (18 and 26 $\left.{ }^{\circ} \mathrm{C}\right)$. The desired temperatures were adjusted with the help of thermostatic water heaters (Rusun, Fish Aquarium Home, Laxhami Nagar, New Delhi, India). Prior to the commencement of the feeding trial, fish were acclimated to the respective water temperatures for 7 days to stabilize their internal mediums and allow metabolic compensation (Castille Jr and Lawrence 1981) and to ensure full thermal adaptation. During this period, the fish were fed with a casein-gelatin based H-440 diet (Halver 2002) thrice a day $(0700,1200,1730 \mathrm{~h})$ until apparent satiation, at each temperature. The apparent satiety was ensured simply by visual observation and the fish were carefully observed during feeding to ensure satiety without overfeeding. The diet was fed as long as the fish actively consumed it at each feeding schedule. Since feed allocation was done till the fish desired to feed and no feed was dispensed once the fish stopped feeding actively, there was no unconsumed feed in the culture tank. A photoperiod of $12 \mathrm{~h}$ light/12 h dark was maintained throughout the experimental period.

For conducting the present experiment, $H$. fossilis fry $(2.97 \pm 0.65 \mathrm{~cm} ; 5.11 \pm 0.34 \mathrm{~g})$ were sorted out from the above acclimated lot and stocked in quadruplet groups ( $n=4$ tanks per treatment) in $70-\mathrm{L}$ circular polyvinyl troughs (water volume $60 \mathrm{~L}$ ). The experiment was conducted in a thermostatic experimental setup. Throughout the experimental period (84 days), temperature was regularly measured three times daily with a thermometer at each feeding schedule. Fish were fed experimental diets in the form of semi-moist cakes in the form of cube $(1 \times 1 \times 1 \mathrm{~cm})$ as per the above feeding schedule. Initial and weekly individual weights were recorded on a top-loading balance (Sartorius CPA- 224S $0.1 \mathrm{mg}$ sensitivity, Goettingen, Germany) after anaesthetizing with tricane methane sulphonate (MS-222; $20 \mathrm{mg} / \mathrm{L}$; Finquel $^{\oplus}$ ). The feeding trial lasted for 84 days. Fish were 
fasted on the day of weekly measurements. A $\mathrm{KMnO}_{4}$ bath was administered after every weighing session $(5 \mathrm{~g} / \mathrm{L}$ for $30 \mathrm{~min}$ ) as a prophylactic measure. Fecal matter, if any, was siphoned off before and after every feeding. The culture troughs were siphoned once every day. The experiments were conducted absolutely as per the guidelines for animal ethics.

\section{Water quality parameters}

Water quality parameters of the troughs were maintained at different temperatures $\left(18\right.$ and $\left.26{ }^{\circ} \mathrm{C}\right)$. Water was sampled from each trough to determine water temperature, dissolved oxygen, free carbon dioxide, total alkalinity, TAN, nitrite, and $\mathrm{pH}$ based on daily measurements following the standard methods (APHA 1992). The $\mathrm{pH}$ was determined by using digital $\mathrm{pH}$ meter ( $\mathrm{pH}$ ep-HI 98107, USA).

\section{Stress resistance response}

At the end of experiment, eight fish were randomly sampled to assess environmental stress (high temperature) trial. The fish were exposed to high temperature $\left(33{ }^{\circ} \mathrm{C}\right)$ and the mortality time was recorded in seconds.

\section{Biochemical composition of fish and experimental diets}

Six subsamples of a pooled sample of 20 fishes were analyzed for initial body composition. At the end of the experiment, all 30 fishes from each replicate of dietary treatments were pooled separately and three subsamples of each replicate from the pooled sample $(n=4)$ were analyzed for final carcass composition. Proximate composition of casein, gelatin, experimental diet, and initial and final body composition was estimated using standard methods (AOAC 1995) for dry matter (oven drying at $105 \pm 1{ }^{\circ} \mathrm{C}$ for $22 \mathrm{~h}$ ), crude protein, (nitrogen estimation using Kjeltec 8400, Hoeganas, Sweden), crude fat (solvent extraction with petroleum ether B.P $40-60{ }^{\circ} \mathrm{C}$ for $2-4 \mathrm{~h}$ by using Soxlet extraction technique, FOSS Avanti automatic 2050 equipment, Sweden), and ash oven incineration at $650{ }^{\circ} \mathrm{C}$ for $2-4 \mathrm{~h}$. To confirm the calculated levels of gross energy of the prepared test diets, each dietary sample was ignited in Gallenkamp ballistic bomb calorimeter (Gallenkamp Ballistic Bomb Calorimeter-CBB 330 010L, Gallenkamp, Loughbrough, UK). The analysis revealed a close agreement with the calculated values of the gross energy density (Table 1 ).

\section{Sample collection}

Evaluation of the hematological parameters involved the determination of the red blood cell count (RBCs $\left.\times 10^{9}\right)$, hemoglobin content $\left(\mathrm{Hb} ; \mathrm{g} \mathrm{dL}^{-1}\right)$, and hematocrit value (Hct\%). At the end of the experiment, fish were anaesthetized with MS-222 (20 mg/L; Finquel $\left.{ }^{\circ}\right)$ before taking the blood samples. The blood samples were then collected from the caudal vein of individual fish (nine fish from each replicate of the treatment) employing heparinized syringes. To avoid blood coagulation, all mixers, pipettes, and test tubes used were rinsed with anticoagulant (3.8\% solution of sodium citrate). Erythrocyte count was determined by an improved Neubauer hematocytometer with Yokoyama's (1974) solution as the diluting medium. Blood hemoglobin was determined spectroscopically (Genesis, UV) following Wong's (1928) method and was expressed in grams per deciliter $(\mathrm{Hb} \mathrm{g} / \mathrm{dL})$. Hematocrit value (Hct\%) was measured by spinning the micro-wintrobe tube containing well mixed blood for about $5 \mathrm{~min}$ at $12,000 \mathrm{~g}$ and then measuring the packed cell volume which was expressed in percentage.

On the final day of the feeding trial, five fish from each tank $(n=4 \times 5)$ were anesthetized (MS-222; $20 \mathrm{mg} / \mathrm{L})$ before subjecting to body measurements. The fish, liver, and viscera of each specimen were weighed by blotting dry on a filter paper, and total length of the fish was taken. The values were recorded to calculate the hepatosomatic index (HSI\%), viscerosomatic index (VSI\%), and condition factor (CF).

\section{Metabolic enzyme activities}

Blood serum was collected after centrifugation at 3000 $\mathrm{rpm}$ for $10 \mathrm{~min}$ and then stored at $-20{ }^{\circ} \mathrm{C}$ in order to analyze aspartate aminotransferase (AST) and alanine aminotransferase (ALT) activities. Biochemical analysis of serum AST and ALT activities were done as per Reitman and Frankel (1957).

\section{Data analyses}

Growth performance of the fish fed experimental diets at different temperatures was measured as a function of the weight gain by calculating following parameters:

$$
\begin{aligned}
& \text { Thermal growth coefficient } \\
& =\left(\text { final body weight }{ }^{0.333} \text {-initial body weight }{ }^{0.333}\right) \\
& \quad / \text { No.of days } \times \text { temperature }^{\circ} \mathrm{C} \times 1000
\end{aligned}
$$

Feed conversion ratio $=$ dry feed fed $(\mathrm{g}) /$ wet weight gain $(\mathrm{g})$

Protein deposition $\mathrm{g} /$ fish $=$ protein gain/protein fed $(\mathrm{g})$

$$
\begin{aligned}
& \text { Hepatosomatic index }(\mathrm{HSI}, \%) \\
& \quad=(\text { liver weight; } \mathrm{g}) /(\text { whole body weight; } \mathrm{g}) \times 100 ;
\end{aligned}
$$

Viscerosomatic index (VSI, \%) $=($ viscera weight $; g) /($ whole body weight $; g)$ $\times 100$;

$$
\begin{aligned}
& \text { Condition factor }\left(\mathrm{CF}, \mathrm{g}^{-1} \mathrm{~cm}^{3}\right) \\
& =(\text { body weight; } \mathrm{g}) /(\text { body length } \mathrm{cm})^{3} \times 100
\end{aligned}
$$

\section{Statistical analyses}

A completely randomized design with four replicates per treatment was used for assessing the optimum protein 
requirement of the fish at two different temperatures. All growth data were subjected to two-way ANOVA as per Snedecor and Cochran (1982) to test any differences and/or the interaction between dietary protein and temperature. Differences among treatment means were determined by Duncan's multiple range test at a $P<$ 0.05 level of significance (Duncan 1955). Relationship between dietary protein level and protein deposition (PD) g/fish was modeled using second-degree polynomial regression analysis (Zeitoun et al. 1976). The protein requirement of fry $H$. fossilis was determined as the point on the graph where the biological response was found to be equal to $95 \%$ of the maximum response. All the statistical analyses were done using Origin (version 6.1; Origin Software, San Clemente, CA).

\section{Results}

\section{Growth performance}

Data on average thermal growth coefficient (TGC), feed conversion ratio (FCR), and protein deposition (PD g/fish) of the fry Heteropneustes fossilis, after 84 days of feeding are summarized in Table 2. Growth performance and feed intake were significantly affected by both dietary protein levels $(P<0.0007)$ and rearing temperature $(P<0.0001)$. However, interactive effects of dietary protein and temperature were not found $(P>0.05) . H$. fossilis fry fed diets containing different levels of protein exhibited superior response in terms of TGC, FCR, and PD g fish ${ }^{-1}$ with $44 \%$ protein at $26^{\circ} \mathrm{C}$ temperature. The groups reared at $18{ }^{\circ} \mathrm{C}$ showed a consistent improvement in their performance up to $40 \%$ protein in the diet. However, the values recorded for TGC, FCR, and PD $g$ fish $^{-1}$ for the groups held at $18{ }^{\circ} \mathrm{C}$ were inferior compared to those held at $26{ }^{\circ} \mathrm{C}$ even though fed with the same level of dietary protein. This indicates that fish held at this temperature failed to express their maximum growth potential.

\section{Carcass quality}

The dietary protein levels and rearing temperatures had significant influence on carcass protein of $H$. fossilis fry (Table 3); however, interactive effects of both were not recorded $(P>0.05)$. Moisture content of $H$. fossilis showed a positive correlation with the increase in dietary protein at both the temperatures $\left(18\right.$ and $\left.26^{\circ} \mathrm{C}\right)$, whereas the carcass fat content showed a negative correlation. Carcass protein tended to increase significantly $(P<$ $0.05)$ in fish fed 40 and $44 \%$ protein $\left(\operatorname{diet} \mathrm{D}_{40}\right.$ and $\left.\mathrm{D}_{44}\right)$ at 18 and $26{ }^{\circ} \mathrm{C}$ temperatures $(P<0.05)$. Moreover, temperature had no significant effect on carcass fat and ash contents.

\section{Metabolic enzyme activities}

As per the results, significant differences $(P<0.05)$ in terms of ALT and AST activities were recorded among

Table 2 Growth, feed conversion, and protein deposition of H. fossilis fry

\begin{tabular}{|c|c|c|c|c|c|c|c|}
\hline Temperature ${ }^{\circ} \mathrm{C}$ & Diet (\% protein) & Ave in wt (g) & Ave fn wt (g) & TGC & FCR & PD g/fish & $\mathrm{Fl} \mathrm{g/fish/day}$ \\
\hline \multirow[t]{7}{*}{18} & D28 & $5.11 \pm 0.02^{\mathrm{Aa}}$ & $22.13 \pm 0.05^{\mathrm{Af}}$ & $0.49 \pm 0.03^{\mathrm{Ae}}$ & $3.57 \pm 0.12^{\mathrm{Aa}}$ & $0.11 \pm 0.03^{\mathrm{Ae}}$ & $0.84 \pm 0.02^{\mathrm{De}}$ \\
\hline & D32 & $5.15 \pm 0.07^{\mathrm{Aa}}$ & $33.21 \pm 0.02^{\mathrm{Ae}}$ & $0.68 \pm 0.07^{\mathrm{Ad}}$ & $2.63 \pm 0.09^{A b}$ & $0.15 \pm 0.04^{\mathrm{Ad}}$ & $1.02 \pm 0.05^{\mathrm{Dd}}$ \\
\hline & D36 & $5.13 \pm 0.05^{\mathrm{Aa}}$ & $46.45 \pm 0.03^{\mathrm{Ad}}$ & $0.87 \pm 0.06^{\mathrm{AC}}$ & $1.99 \pm 0.07^{A C}$ & $0.19 \pm 0.03^{\mathrm{AC}}$ & $1.14 \pm 0.04^{C c}$ \\
\hline & D40 & $5.12 \pm 0.09^{\mathrm{Aa}}$ & $59.98 \pm 0.05^{\mathrm{Aa}}$ & $1.01 \pm 0.02^{\mathrm{Aa}}$ & $1.61 \pm 0.09^{\mathrm{Af}}$ & $0.23 \pm 0.04^{\mathrm{Aa}}$ & $1.23 \pm 0.03^{\mathrm{Aa}}$ \\
\hline & D44 & $5.14 \pm 0.02^{\mathrm{Aa}}$ & $58.65 \pm 0.02^{\mathrm{Aa}}$ & $0.99 \pm 0.01^{\mathrm{Aa}}$ & $1.67 \pm 0.11^{\mathrm{Ae}}$ & $0.21 \pm 0.01^{\mathrm{Ab}}$ & $1.24 \pm 0.05^{\mathrm{Aa}}$ \\
\hline & D48 & $5.15 \pm 0.01^{\mathrm{Aa}}$ & $56.64 \pm 0.03^{\mathrm{Ab}}$ & $0.94 \pm 0.02^{\mathrm{Ab}}$ & $1.69 \pm 0.05^{\mathrm{Ae}}$ & $0.19 \pm 0.03^{A C}$ & $1.21 \pm 0.04^{\mathrm{Aa}}$ \\
\hline & D52 & $5.13 \pm 0.01^{\mathrm{Aa}}$ & $53.43 \pm 0.03^{A c}$ & $0.89 \pm 0.03^{A C}$ & $1.79 \pm 0.13^{\mathrm{Ad}}$ & $0.16 \pm 0.02^{\mathrm{Ad}}$ & $1.20 \pm 0.03^{\mathrm{Bb}}$ \\
\hline \multirow[t]{11}{*}{26} & D28 & $5.15 \pm 0.02^{\mathrm{Aa}}$ & $23.45 \pm 0.05^{f}$ & $0.56 \pm 0.04^{F f}$ & $3.44 \pm 0.02^{\mathrm{Aa}}$ & $0.12 \pm 0.03^{\mathrm{Ae}}$ & $0.87 \pm 0.02^{\mathrm{Ff}}$ \\
\hline & D32 & $5.11 \pm 0.07^{\mathrm{Aa}}$ & $34.34 \pm 0.02^{e}$ & $0.76 \pm 0.07^{\mathrm{Dd}}$ & $2.56 \pm 0.09^{\mathrm{Ab}}$ & $0.17 \pm 0.04^{\mathrm{Ad}}$ & $1.04 \pm 0.05^{\mathrm{Ee}}$ \\
\hline & D36 & $5.14 \pm 0.05^{\mathrm{Aa}}$ & $47.13 \pm 0.03^{d}$ & $0.94 \pm 0.06^{c c}$ & $1.87 \pm 0.07^{\mathrm{Ac}}$ & $0.21 \pm 0.06^{A C}$ & $1.09 \pm 0.04^{\mathrm{Ee}}$ \\
\hline & D40 & $5.12 \pm 0.09^{\mathrm{Aa}}$ & $56.59 \pm 0.05^{c}$ & $1.04 \pm 0.02^{\mathrm{Bb}}$ & $1.62 \pm 0.19^{\mathrm{Ad}}$ & $0.23 \pm 0.04^{\mathrm{Ab}}$ & $1.16 \pm 0.05^{\mathrm{Cd}}$ \\
\hline & D44 & $5.11 \pm 0.02^{\mathrm{Aa}}$ & $69.12 \pm 0.02^{\mathrm{a}}$ & $1.08 \pm 0.01^{\mathrm{Aa}}$ & $1.48 \pm 0.01^{\mathrm{Af}}$ & $0.26 \pm 0.01^{\mathrm{Aa}}$ & $1.31 \pm 0.03^{\mathrm{Aa}}$ \\
\hline & D48 & $5.14 \pm 0.01^{\mathrm{Aa}}$ & $67.14 \pm 0.03^{\mathrm{a}}$ & $0.99 \pm 0.02^{\mathrm{Bb}}$ & $1.49 \pm 0.01^{\mathrm{Af}}$ & $0.24 \pm 0.03^{\mathrm{Ab}}$ & $1.28 \pm 0.01^{\mathrm{Ab}}$ \\
\hline & D52 & $5.12 \pm 0.01^{\mathrm{Aa}}$ & $61.64 \pm 0.03^{b}$ & $0.93 \pm 0.02^{c c}$ & $1.57 \pm 0.01^{\mathrm{Ae}}$ & $0.21 \pm 0.04^{A C}$ & $1.23 \pm 0.03^{B C}$ \\
\hline & $P$ value & & & & & & \\
\hline & Dietary protein & NS & 0.0007 & 0.003 & 0.005 & NS & 0.002 \\
\hline & Temperature & NS & 0.0001 & 0.001 & 0.003 & 0.0001 & 0.005 \\
\hline & Dietary protein $x$ temp & NS & NS & NS & NS & NS & NS \\
\hline
\end{tabular}

Ave in wt average initial weight, Ave fn wt average final weight, TGC thermal growth coefficient, $F C R$ feed conversion ratio, $P D$ protein deposition, $F /$ feed intake, different upper case letter indicate significant differences $(P<0.05)$ between temperatures whereas different with superscripts indicate significant differences between dietary protein levels; NS nonsignificant $(P>0.05)$ 
Table 3 Whole body carcass quality of fry Heteropneustes fossilis

\begin{tabular}{|c|c|c|c|c|c|}
\hline Temp. ${ }^{\circ} \mathrm{C}$ & Diet (\% protein) & Moisture (\%) & Protein (\%) & Fat (\%) & Ash (\%) \\
\hline \multirow[t]{7}{*}{$\overline{18}$} & $D_{28}$ & $76.68 \pm 0.02^{\mathrm{Aa}}$ & $12.15 \pm 0.05^{\complement c}$ & $6.93 \pm 0.03^{\mathrm{Aa}}$ & $3.98 \pm 0.02^{\mathrm{Aa}}$ \\
\hline & $D_{32}$ & $76.77 \pm 0.07^{\mathrm{Aa}}$ & $13.13 \pm 0.02^{\mathrm{Bb}}$ & $5.29 \pm 0.07^{\mathrm{Ab}}$ & $3.95 \pm 0.09^{\mathrm{Aa}}$ \\
\hline & $D_{36}$ & $75.98 \pm 0.05^{\mathrm{Bb}}$ & $13.68 \pm 0.03^{\mathrm{Bb}}$ & $4.66 \pm 0.06^{\mathrm{Ac}}$ & $3.95 \pm 0.07^{\mathrm{Aa}}$ \\
\hline & $\mathrm{D}_{40}$ & $76.21 \pm 0.09^{\mathrm{Bb}}$ & $14.96 \pm 0.05^{\mathrm{Aa}}$ & $3.19 \pm 0.02^{\mathrm{Ad}}$ & $3.88 \pm 0.09^{\mathrm{Ab}}$ \\
\hline & $\mathrm{D}_{44}$ & $76.68 \pm 0.02^{\mathrm{Bb}}$ & $14.97 \pm 0.02^{\mathrm{Aa}}$ & $3.21 \pm 0.01^{\mathrm{Ad}}$ & $3.81 \pm 0.01^{\mathrm{Ab}}$ \\
\hline & $\mathrm{D}_{48}$ & $75.88 \pm 0.01^{\mathrm{Cb}}$ & $14.95 \pm 0.03^{\mathrm{Aa}}$ & $4.21 \pm 0.02^{A c}$ & $3.80 \pm 0.01^{\mathrm{Ab}}$ \\
\hline & $D_{52}$ & $76.35 \pm 0.01^{\mathrm{Bb}}$ & $14.89 \pm 0.03^{\mathrm{Aa}}$ & $4.26 \pm 0.02^{\mathrm{Ac}}$ & $3.81 \pm 0.01^{\mathrm{Ab}}$ \\
\hline \multirow[t]{11}{*}{26} & $\mathrm{D}_{28}$ & $76.91 \pm 0.02^{\mathrm{Aa}}$ & $12.81 \pm 0.05^{\mathrm{Ee}}$ & $6.88 \pm 0.03^{\mathrm{Aa}}$ & $3.95 \pm 0.02^{\mathrm{Aa}}$ \\
\hline & $D_{32}$ & $76.11 \pm 0.07^{\mathrm{Aa}}$ & $13.98 \pm 0.02^{\mathrm{Dd}}$ & $6.13 \pm 0.07^{\mathrm{Ab}}$ & $3.96 \pm 0.09^{\mathrm{Aa}}$ \\
\hline & $D_{36}$ & $76.45 \pm 0.05^{\mathrm{Aa}}$ & $14.41 \pm 0.03^{C c}$ & $4.98 \pm 0.06^{\mathrm{Ac}}$ & $3.94 \pm 0.07^{\mathrm{Aa}}$ \\
\hline & $\mathrm{D}_{40}$ & $75.69 \pm 0.09^{B b}$ & $15.19 \pm 0.05^{\mathrm{Bb}}$ & $3.54 \pm 0.02^{\mathrm{Ae}}$ & $3.76 \pm 0.09^{\mathrm{Ab}}$ \\
\hline & $\mathrm{D}_{44}$ & $75.21 \pm 0.02^{\mathrm{Bb}}$ & $16.98 \pm 0.02^{\mathrm{Aa}}$ & $4.16 \pm 0.01^{\mathrm{Ad}}$ & $3.74 \pm 0.01^{\mathrm{Ab}}$ \\
\hline & $\mathrm{D}_{48}$ & $75.11 \pm 0.01^{\mathrm{Bb}}$ & $16.95 \pm 0.03^{\mathrm{Aa}}$ & $4.26 \pm 0.02^{\mathrm{Ad}}$ & $3.72 \pm 0.01^{\mathrm{Ab}}$ \\
\hline & $D_{52}$ & $75.51 \pm 0.01^{\mathrm{Bb}}$ & $16.93 \pm 0.03^{\mathrm{Aa}}$ & $4.89 \pm 0.02^{\mathrm{Ac}}$ & $3.75 \pm 0.01^{\mathrm{Ab}}$ \\
\hline & $P$ value & & & & \\
\hline & Dietary protein & 0.003 & 0.002 & 0.0001 & 0.004 \\
\hline & Temperature & 0.0001 & 0.007 & NS & NS \\
\hline & Dietary protein $x$ temp & NS & NS & NS & NS \\
\hline
\end{tabular}

NS non-significant $(P>0.05)$

Different upper case superscripts indicate significant differences $(P<0.05)$ between temperatures, whereas different with superscripts indicate significant differences between dietary protein levels

the two experimental groups reared at two different temperatures. The values of ALT and AST were significantly $(P<0.05)$ higher among the groups reared at 18 ${ }^{\circ} \mathrm{C}$ temperature compared to those reared at $26{ }^{\circ} \mathrm{C}$ water temperature. Also, serum enzymes of $H$. fossilis seem not to be much affected by different protein levels in this study but were more affected by water temperatures (Table 4). However, the interactive effects of dietary protein and temperature were not found.

\section{Hematological parameters}

Dietary protein and temperature had significant impact on hematological parameters $(P<0.05)$ with no interactive effects of both. Fish fed diet containing 28\% protein achieved the lowest hematological values at both the temperatures. RBCs, $\mathrm{Hb}$ g/dL, and Hct\% increased with increasing levels of dietary protein up to $44 \%$ (diet $\mathrm{D}_{44}$ ), both at 18 and $26{ }^{\circ} \mathrm{C}$ rearing temperatures (Table 4). Thereafter, the above hematological parameters remained almost the same in fish fed $48 \%$ (diet $\mathrm{D}_{48}$ ) dietary protein and the exhibited a decline with further increase in the dietary protein intake at $52 \%$ (diet $\mathrm{D}_{52}$ ). However, at $18{ }^{\circ} \mathrm{C}$, the magnitude of response in above values was comparatively lower than that attained in fish raised at $26{ }^{\circ} \mathrm{C}$ for the same dietary protein level.

\section{Somatic indices}

VSI and HSI decreased with increase in dietary protein levels up to $44 \%$ and increased in fish fed dietary protein beyond $44 \%$ at $48\left(D_{48}\right)$ and $52 \%$ protein $\left(D_{52}\right)$. Hepatosomatic index (HSI) was found to be influenced by the levels of dietary protein and temperatures but no interaction occurred, while viscerosomatic index (VSI) was affected by only diets and not by temperatures (Table 5).

\section{Stress resistance response}

Resistance rate to thermal stress increased significantly $(P<0.05)$ among the groups reared at $26{ }^{\circ} \mathrm{C}$ water temperature than those reared at $18{ }^{\circ} \mathrm{C}$ (Table 5). The stress resistance response remained best for the groups fed with $44 \%$ dietary protein. This parameter was affected by both dietary protein levels and rearing temperatures; however, no interactive effects of both were noted $(P>0.23)$. The normal values of water quality parameters during the entire length of experiment are provided in Table 6.

\section{Protein requirement}

Based on the above response parameters, second-degree polynomial regression analyses were performed to study the relationships between dietary protein levels and the protein deposition and were expressed in the form of $Y$ 
Table 4 Metabolic enzymes activities and hematological parameters of fry Heteropneustes fossilis

\begin{tabular}{|c|c|c|c|c|c|c|c|}
\hline \multirow{2}{*}{$\frac{\text { Temp. }{ }^{\circ} \mathrm{C}}{18}$} & \multirow{2}{*}{$\begin{array}{l}\text { Diet (\% protein) } \\
D_{28}\end{array}$} & \multirow{2}{*}{$\frac{\mathrm{AST}(\mathrm{IU} / \mathrm{L})}{54.77 \pm 0.03^{\mathrm{Bb}}}$} & \multirow{2}{*}{$\frac{\mathrm{ALT}(\mathrm{IU} / \mathrm{L})}{57.11 \pm 0.01^{\mathrm{Aa}}}$} & \multirow{2}{*}{$\begin{array}{l}\mathrm{Hct} \% \\
21.24 \pm 0.02^{\mathrm{Ee}}\end{array}$} & \multicolumn{2}{|c|}{$\mathrm{Hb} \mathrm{g} / \mathrm{dL}$} & \multirow{2}{*}{$\frac{\operatorname{RBCs}\left(\times 10^{9}\right)}{2.67 \pm 0.02^{\mathrm{Dd}}}$} \\
\hline & & & & & \multicolumn{2}{|c|}{$6.14 \pm 0.02^{e}$} & \\
\hline & $D_{32}$ & $53.11 \pm 0.05^{c c}$ & $55.23 \pm 0.02^{\mathrm{Bb}}$ & $23.97 \pm 0.09^{\mathrm{Dd}}$ & \multicolumn{2}{|c|}{$6.98 \pm 0.02^{d}$} & $2.79 \pm 0.02^{C c}$ \\
\hline & $D_{36}$ & $52.21 \pm 0.02^{D d}$ & $54.33 \pm 0.05^{\mathrm{Cc}}$ & $27.43 \pm 0.07^{C c}$ & \multicolumn{2}{|c|}{$7.78 \pm 0.02^{c}$} & $2.81 \pm 0.02^{\mathrm{Bb}}$ \\
\hline & $\mathrm{D}_{40}$ & $51.33 \pm 0.04^{\mathrm{De}}$ & $54.11 \pm 0.03^{C c}$ & $32.91 \pm 0.09^{\mathrm{Aa}}$ & \multicolumn{2}{|c|}{$8.83 \pm 0.02^{b}$} & $3.11 \pm 0.02^{\mathrm{Aa}}$ \\
\hline & $\mathrm{D}_{44}$ & $51.59 \pm 0.01^{\mathrm{De}}$ & $54.21 \pm 0.02^{\mathrm{Cc}}$ & $32.97 \pm 0.01^{\mathrm{Aa}}$ & \multicolumn{2}{|c|}{$9.97 \pm 0.02^{a}$} & $2.98 \pm 0.02^{\mathrm{Aa}}$ \\
\hline & $D_{48}$ & $54.99 \pm 0.03^{\mathrm{Bb}}$ & $54.65 \pm 0.04^{C c}$ & $31.89 \pm 0.01^{\mathrm{Aa}}$ & \multicolumn{2}{|c|}{$9.94 \pm 0.02^{\mathrm{a}}$} & $2.85 \pm 0.02^{\mathrm{Bb}}$ \\
\hline & $D_{52}$ & $55.68 \pm 0.02^{\mathrm{Aa}}$ & $55.98 \pm 0.01^{\mathrm{Bb}}$ & $29.78 \pm 0.01^{\mathrm{Bb}}$ & \multicolumn{2}{|c|}{$9.84 \pm 0.02^{a}$} & $2.64 \pm 0.02^{\mathrm{Dd}}$ \\
\hline \multirow[t]{11}{*}{26} & $\mathrm{D}_{28}$ & $53.99 \pm 0.02^{\mathrm{Aa}}$ & $44.93 \pm 0.02^{\mathrm{Aa}}$ & $22.23 \pm 0.02^{\mathrm{Ee}}$ & \multicolumn{2}{|c|}{$6.91 \pm 0.02^{e}$} & $2.97 \pm 0.02^{C c}$ \\
\hline & $D_{32}$ & $52.65 \pm 0.02^{\mathrm{Ab}}$ & $44.18 \pm 0.03^{\mathrm{Aa}}$ & $25.51 \pm 0.09^{\mathrm{Dd}}$ & \multicolumn{2}{|c|}{$7.19 \pm 0.02^{d}$} & $2.99 \pm 0.02^{C c}$ \\
\hline & $D_{36}$ & $51.96 \pm 0.02^{B C}$ & $42.23 \pm 0.05^{\mathrm{Bb}}$ & $28.64 \pm 0.07^{c c}$ & \multicolumn{2}{|c|}{$8.32 \pm 0.02^{c}$} & $3.14 \pm 0.02^{B b}$ \\
\hline & $\mathrm{D}_{40}$ & $51.14 \pm 0.02^{B C}$ & $39.18 \pm 0.02^{C c}$ & $32.93 \pm 0.09^{\mathrm{Bb}}$ & \multicolumn{2}{|c|}{$9.24 \pm 0.02^{b}$} & $3.23 \pm 0.02^{\mathrm{Bb}}$ \\
\hline & $\mathrm{D}_{44}$ & $49.13 \pm 0.02^{\mathrm{Ce}}$ & $33.98 \pm 0.04^{\mathrm{Ef}}$ & $33.92 \pm 0.01^{\mathrm{Aa}}$ & \multicolumn{2}{|c|}{$10.59 \pm 0.02^{a}$} & $3.97 \pm 0.02^{\mathrm{Aa}}$ \\
\hline & $\mathrm{D}_{48}$ & $49.88 \pm 0.02^{\mathrm{De}}$ & $35.98 \pm 0.03^{\mathrm{De}}$ & $32.97 \pm 0.01^{\mathrm{Bb}}$ & \multicolumn{2}{|c|}{$10.21 \pm 0.02^{a}$} & $3.75 \pm 0.02^{\mathrm{Aa}}$ \\
\hline & $D_{52}$ & $50.97 \pm 0.02^{\mathrm{Dd}}$ & $36.98 \pm 0.01^{\mathrm{Dd}}$ & $31.91 \pm 0.01^{\mathrm{Bb}}$ & \multicolumn{2}{|c|}{$10.11 \pm 0.02^{a}$} & $3.88 \pm 0.02^{\mathrm{Aa}}$ \\
\hline & \multicolumn{7}{|l|}{$P$ value } \\
\hline & Dietary protein & 0.003 & 0.0005 & 0.001 & 0.006 & 0.002 & 0.0001 \\
\hline & Temperature & 0.008 & 0.0001 & 0.004 & 0.003 & NS & 0.0009 \\
\hline & Dietary protein $\times$ temp & NS & NS & NS & NS & NS & NS \\
\hline
\end{tabular}

AST aspartate amino transferases, ALT alanine amino transferases, Hct hematocrit, $H b$ hemoglobin, RBCs red blood cells count

Different upper case superscripts indicate significant differences $(P<0.05)$ between temperatures, whereas different with superscripts indicate significant

differences between dietary protein levels; NS non-significant $(P>0.05)$

Table 5 Somatic indices and stress resistance response of fry Heteropneustes fossilis

\begin{tabular}{|c|c|c|c|c|c|}
\hline Temp. ${ }^{\circ} \mathrm{C}$ & Diet (\% protein) & HSI (\%) & VSI (\%) & CF (\%) & Stress resistance response (mortality time measured in seconds) \\
\hline \multirow[t]{7}{*}{18} & $D_{28}$ & $3.41 \pm 0.02^{\mathrm{Aa}}$ & $5.12 \pm 0.05^{\mathrm{a}}$ & $0.94 \pm 0.03^{\mathrm{Ff}}$ & $150 \pm 0.03^{F f}$ \\
\hline & $D_{32}$ & $2.33 \pm 0.07^{\mathrm{Bb}}$ & $3.49 \pm 0.02^{b}$ & $1.32 \pm 0.07^{\mathrm{Ee}}$ & $180 \pm 0.03^{\mathrm{Ee}}$ \\
\hline & $D_{36}$ & $1.70 \pm 0.05^{\mathrm{Cc}}$ & $2.45 \pm 0.03^{c}$ & $1.49 \pm 0.06^{\mathrm{Dd}}$ & $250 \pm 0.03^{\mathrm{Dd}}$ \\
\hline & $\mathrm{D}_{40}$ & $1.44 \pm 0.09^{\mathrm{Ff}}$ & $2.16 \pm 0.05^{e}$ & $1.68 \pm 0.02^{\mathrm{Aa}}$ & $360 \pm 0.03^{c c}$ \\
\hline & $\mathrm{D}_{44}$ & $1.40 \pm 0.02^{\mathrm{Ff}}$ & $2.11 \pm 0.02^{\mathrm{e}}$ & $1.67 \pm 0.01^{\mathrm{Aa}}$ & $440 \pm 0.03^{\mathrm{Bb}}$ \\
\hline & $\mathrm{D}_{48}$ & $1.53 \pm 0.01^{\mathrm{Ee}}$ & $2.30 \pm 0.03^{d}$ & $1.64 \pm 0.02^{\mathrm{Ab}}$ & $580 \pm 0.03^{\mathrm{Aa}}$ \\
\hline & $D_{52}$ & $1.67 \pm 0.01^{\mathrm{Dd}}$ & $2.53 \pm 0.03^{d}$ & $1.61 \pm 0.02^{\mathrm{Ac}}$ & $360 \pm 0.03^{c c}$ \\
\hline \multirow[t]{11}{*}{26} & $D_{28}$ & $3.16 \pm 0.02^{\mathrm{Aa}}$ & $4.97 \pm 0.05^{\mathrm{a}}$ & $0.99 \pm 0.03^{\mathrm{Ff}}$ & $280 \pm 0.03^{\mathrm{Ee}}$ \\
\hline & $D_{32}$ & $2.11 \pm 0.07^{\mathrm{Bb}}$ & $3.31 \pm 0.02^{b}$ & $1.34 \pm 0.07^{\mathrm{Ee}}$ & $390 \pm 0.03^{\mathrm{Dd}}$ \\
\hline & $D_{36}$ & $1.51 \pm 0.05^{\complement c}$ & $2.37 \pm 0.03^{c}$ & $1.55 \pm 0.06^{\mathrm{Dd}}$ & $470 \pm 0.03^{c c}$ \\
\hline & $\mathrm{D}_{40}$ & $1.30 \pm 0.09^{\mathrm{Ee}}$ & $2.05 \pm 0.05^{d}$ & $1.69 \pm 0.02^{\mathrm{Aa}}$ & $540 \pm 0.03^{\mathrm{Bb}}$ \\
\hline & $D_{44}$ & $1.27 \pm 0.02^{\mathrm{Ee}}$ & $2.01 \pm 0.02^{d}$ & $1.70 \pm 0.01^{\mathrm{Aa}}$ & $630 \pm 0.03^{\mathrm{Aa}}$ \\
\hline & $\mathrm{D}_{48}$ & $1.41 \pm 0.01^{\mathrm{Dd}}$ & $2.21 \pm 0.03^{c}$ & $1.68 \pm 0.02^{\mathrm{Ab}}$ & $580 \pm 0.03^{\mathrm{Bb}}$ \\
\hline & $D_{52}$ & $1.57 \pm 0.01^{\mathrm{Cc}}$ & $2.47 \pm 0.03^{c}$ & $1.64 \pm 0.02^{\mathrm{BC}}$ & $350 \pm 0.03^{D d}$ \\
\hline & $P$ value & & & & \\
\hline & Dietary protein & 0.003 & 0.0005 & 0.001 & 0.006 \\
\hline & Temperature & 0.008 & 0.0001 & 0.001 & 0.003 \\
\hline & Dietary protein $x$ temp & NS & NS & NS $(P>0.267)$ & NS $(P>0.23)$ \\
\hline
\end{tabular}

HSI hepatosomatic index, VSI viscerosomatic index, CF condition factor

Different upper case superscripts indicate significant differences $(P<0.05)$ between temperatures, whereas different with superscripts indicate significant differences between dietary protein levels; NS non-significant $(P>0.05)$ 
Table 6 Water quality parameters (Based on daily measurements)

\begin{tabular}{lll}
\hline Parameters & \multicolumn{2}{l}{ Temperatures $\left({ }^{\circ} \mathrm{C}\right)$} \\
\cline { 2 - 3 } & $18^{\circ} \mathrm{C}$ & $26{ }^{\circ} \mathrm{C}$ \\
\hline Temperature $(\mathrm{C})$ & $20.1 \pm 0.3$ & $26.2 \pm 0.1$ \\
Dissolved oxygen $(\mathrm{mg} / \mathrm{L})$ & $7.1 \pm 0.2$ & $6.7 \pm 0.4$ \\
$\mathrm{pH}$ & $7.6 \pm 0.3$ & $7.2 \pm 0.2$ \\
Free $\mathrm{CO}_{2}(\mathrm{mg} / \mathrm{L})$ & $5.7 \pm 0.5$ & $6.3 \pm 0.5$ \\
Total alkalinity $(\mathrm{mg} / \mathrm{L})$ & $74.9 \pm 0.7$ & $75.6 \pm 0.4$ \\
Total $\mathrm{NH}_{3}-\mathrm{N}(\mathrm{mg} / \mathrm{L})$ & $0.02 \pm 0.01$ & $0.03 \pm 0.01$ \\
Nitrite $\left(\mathrm{NO}_{2}, \mathrm{mg} / \mathrm{L}\right)^{\mathrm{a}}$ & - & \\
\end{tabular}

Mean \pm SD $(n=183)$. Recorded thrice daily at 07:00, 12:00, and 17:30 h andetectable

$=a X^{2=}+b X+c$. The value of $X$ that corresponds to $\mathrm{Y}_{95 \% \max }$ was defined as the requirement. PD g/fish data $\left(\mathrm{Y}_{95 \% \max }\right)$ to dietary protein levels $(X)$ was subjected to a second-degree polynomial regression analysis. The curve attained its $95 \%$ maximum response at 40.8 and $41.8 \%$ protein of the diet (Fig. 1) at $18{ }^{\circ} \mathrm{C}$ and $26{ }^{\circ} \mathrm{C}$ water temperature, respectively.

\section{Discussion}

The aim of this study is to assess the influence of water temperature on dietary protein requirement, protein deposition, carcass quality, and hematological parameters of fry $H$. fossilis. Temperature is a pervasive factor affecting food intake, growth, and food conversion of fish (Fry 1947; Brett 1979). Since water temperature has potent influence on metabolic rate and energy expenditure affecting nutrient requirement and growth performance of the poikilothermic vertebrates including fish (Brett 1979; Dutta 1994; Bhikajee and Gobin 1998), its influence on nutrient requirement and growth warrant thorough investigation.

Several studies have reported that the specific water temperature range showed that the faster growth and low temperature causes sluggishness by retarding the digestion speeding of fish (Bailey and Alanara 2006). Some researchers have found that the digestion rate has been increased as the temperature increases (Turker 2009). Environmental temperature is one of the most important ecological factors which also influence the behavior and physiological process of aquatic animals (Xia and Li 2010).

The results showed that growth in terms of thermal growth coefficient, feed conversion, and protein deposition of the fish attained best values with dietary protein levels of 40 and $44 \%$ at 18 and $26^{\circ} \mathrm{C}$ water temperatures, respectively. The fish attained its maximum growth potential in terms of TWG, FCR, protein deposition, and body protein content at $26{ }^{\circ} \mathrm{C}$ water temperature. Carcass protein content exhibited best value for the groups fed $44 \%$ dietary protein at $26{ }^{\circ} \mathrm{C}$ temperature. Hematological parameters also attained their normal physiological range with $44 \%$ protein diet at $26{ }^{\circ} \mathrm{C}$.

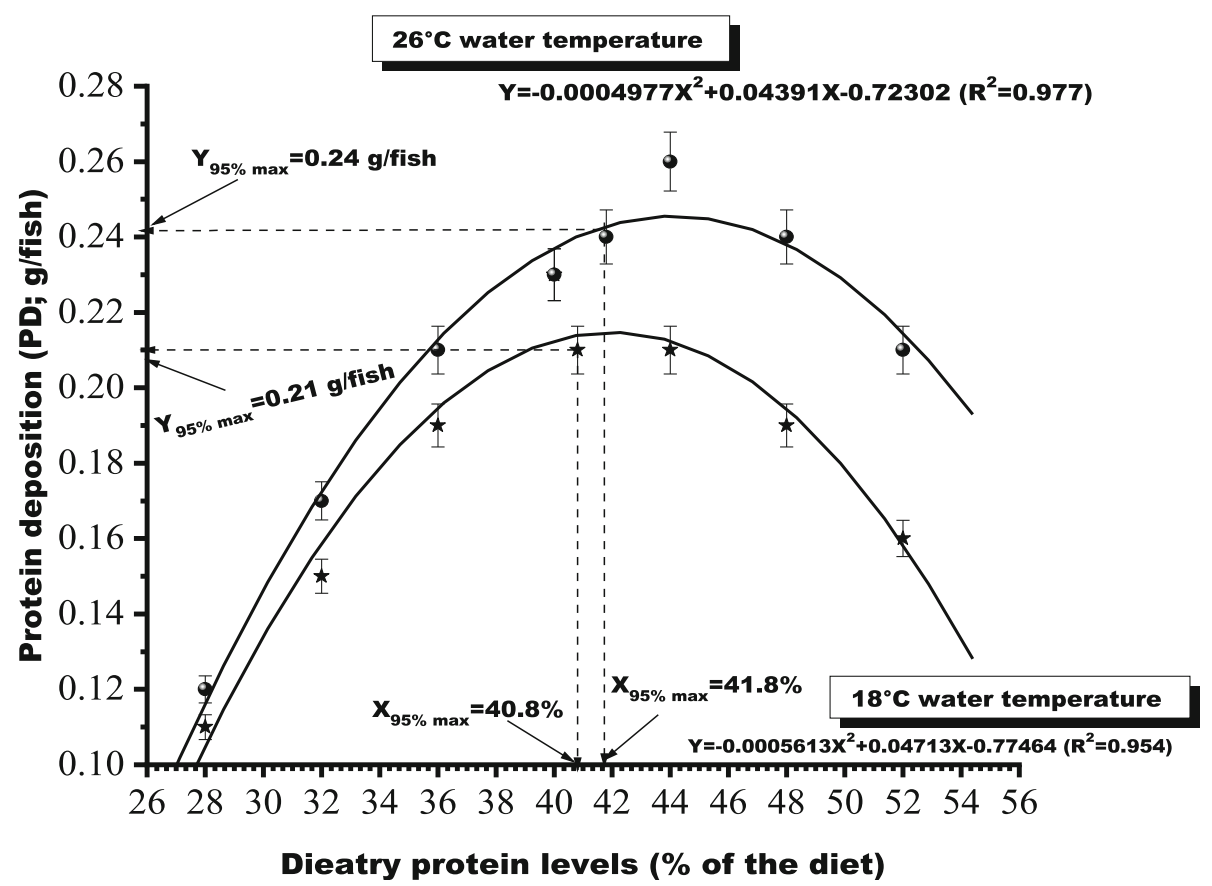

Fig. 1 Second-degree polynomial regression analysis of protein deposition (PD g/fish) against varying levels of dietary protein at two temperatures 
Inferior values for these parameters were recorded for the groups held at $18{ }^{\circ} \mathrm{C}$ water temperature presumably due to the fact that the body metabolism occurs at a slower rate if fish are held at sub-optimum or lower water temperatures. Similar trend has also been reported by Peres and Oliva-Teles (1999) and Ozorio et al. (2006) in various other cultivable finfish species where fish held at $18{ }^{\circ} \mathrm{C}$ water temperature could not attain their maximum growth potential even if supplied with the required level of dietary protein. Growth performance and feed intake were significantly affected by both dietary protein levels and rearing temperature. However, interactive effects of dietary protein and temperature were not found. Depressed growth, lower feed intake, and protein deposition were more commonly noted for the groups reared at $18{ }^{\circ} \mathrm{C}$. Even the groups fed dietary protein at 40 to $44 \%$ could not attain their maximum growth potential and feed intake at $18{ }^{\circ} \mathrm{C}$ as attained by the groups fed same diets at $26{ }^{\circ} \mathrm{C}$. The study clearly indicates that dietary protein requirement of $H$. fossilis for maximizing the growth, feed conversion, and for attaining best values for hematological parameters ranges somewhere between 40.8 and $41.8 \%$ at $26{ }^{\circ} \mathrm{C}$ water temperature.

Choice of mathematical models in estimating the dietary level for a limiting nutrient is very important. Some studies show better regression coefficients when a broken-line analysis $(Y=a+b X)$ is used (Baker 1986), whereas some respond better to a second-degree polynomial regression analysis (Tacon and Cowey 1985; ElDakar et al. 2011). In this study, although data were fitted best for broken-line regression analysis, the $p$ value of the $t$ test for estimated coefficient was not found significantly different from zero for broken-line regression analysis. Therefore, second-degree polynomial regression analysis which exhibited a significant $p$ value of the $t$ test for the estimated coefficient has been employed for quantifying dietary protein requirement of $H$. fossilis fry. The requirements have been determined at $95 \%$ confidence interval. Based on above analyses, $44 \%$ dietary protein at $26{ }^{\circ} \mathrm{C}$ water temperature appears to be optimum for growth of $H$. fossilis fry and the curve did not reach a plateau until $44 \%$ dietary protein level. The second-degree polynomial fitting of protein deposition values at $95 \%$ maximum response exhibited optimum dietary protein requirement of fry $H$. fossilis between 40.8 and $41.8 \%$ (Fig. 1 ) at $26{ }^{\circ} \mathrm{C}$ water temperature. This level fall in the range of the previously reported dietary protein requirements of some other catfish species such as young $H$. fossilis 40-43\% (Siddiqui and Khan 2009), Cyprinus carpio 41.25\% (Ahmed and Maqbool 2017), higher than that for walking catfish, Clarias batrachus 36\% (Singh et al. 2009), spotted snake-head, Channa punctatus 40\% (Zehra and Khan 2012), and marbled spinefoot rabbitfish, Siganus rivulatus 40\% (El-Dakar et al. 2011) and is lower than the requirements reported for African catfish, Clarias gariepinus 43\% (Farhat 2011), Mystus nemurus 42\% (Khan et al. 1993), Malaysian catfish, bagrid catfish, Mystus nemurus 44\% (Ng et al. 2001), and striped murrel, Channa striatus 55\% (Kumar et al. 2010).

The PD g/fish increased progressively with the increase in dietary protein up to $40 \%$ for the groups held at $18{ }^{\circ} \mathrm{C}$ and up to $44 \%$ for the groups held at $26{ }^{\circ} \mathrm{C}$ water temperatures, respectively. The $\mathrm{PD} /$ fish value attained by the groups reared at $18{ }^{\circ} \mathrm{C}$ was somewhat lower than that attained by the groups at the same level of dietary protein at $26^{\circ} \mathrm{C}$. This may probably be due to the reason that an increase in temperature at $26{ }^{\circ} \mathrm{C}$ might have increased the activity of digestive enzymes accelerating digestion of the nutrients, thus resulting in better growth (Shcherbina and Kazlauskene 1971) in the form of deposited protein. Hilge (1985) found that the optimum temperature for best growth of European catfish, Silurus glanis was almost within the range of 18 to $26{ }^{\circ} \mathrm{C}$ with best results noted at $27{ }^{\circ} \mathrm{C}$. Brown et al. (1989) reported a $40 \%$ increase in growth rate of cod reared at $8.3{ }^{\circ} \mathrm{C}$ compared with $4.5{ }^{\circ} \mathrm{C}$. This value was similar to that of Otterle et al. (1994), who reported an increase in growth rate of about $50 \%$ with each $4{ }^{\circ} \mathrm{C}$ increase in temperature between 6 and $14{ }^{\circ} \mathrm{C}$. Protein deposition in this study was found to decrease for the groups fed dietary protein above $44 \%$ in diets $\mathrm{D}_{48}(48 \%)$ and $D_{52}(52 \%)$ irrespective of the water temperatures. Proteins represent a very important source of energy in fishes. Since teleosts have developed the capacity for converting amino acid to glucose (Bever et al. 1981) by gluconeogenesis which is utilized for energy production through TCA cycle intermediates (Kumar 1999), it is reasonable to assume that the decline in protein deposition at higher levels of dietary protein for the groups fed diets $\mathrm{D}_{48}$ (48\% protein) and $\mathrm{D}_{52}(52 \%$ protein) may probably be due to catabolism of excess protein for energy purposes thus reducing its deposition for tissue building or growth.

There are conflicting findings about the effect of dietary protein levels on the efficiency of protein utilization in the literatures. Lee et al. (2001) reported an increase in protein utilization efficiency with the increased intake of dietary protein by the fish, whereas Duan et al. (2001) and Lee et al. (2003) did not find any significant influence of dietary protein on efficiency of protein utilization. However, Kim et al. (2001), Kim and Lee (2009), and Gullu et al. (2008) pointed out a decrease in protein utilization with increasing dietary protein above optimum level which is in agreement with the present results. Davis and Stickney (1978) stated that fish convert protein more efficiently when fed dietary protein 
level less than optimal level that yields the maximum growth and feed efficiency. Steffens (1981) also reported that raising the dietary protein level improves the growth rate and food conversion but reduces the protein productive value in Salmo gairdneri and Cyprinus carpio. Similar findings were evident in this study where fish fed $48 \%$ and more protein manifested reduction in protein deposition.

The protein requirements or protein utilization of fish is also influenced by dietary non-protein energy levels (Dias et al. 1998; Lupatsch et al. 2001; Tibbetts et al. 2005; Wang et al. 2006). Hence, it is possible to reduce the dietary protein level to a certain degree by increasing non-protein energy and directing protein to growth rather than energetic use in a number of fish species (Forster and Hardy 2000). A protein-sparing effect is generally more pronounced at low protein levels rather than high levels (Dias et al. 1998; Tibbetts et al. 2005) mainly because of the preferential use of protein as an energy source by fish at high protein levels (Tibbetts et al. 2005). Cowey (1979) has also suggested that any change in dietary energy content changes the optimal protein requirement of the fish. Although in this study, the diets were formulated to be isocaloric and the digestible energy content of the diets was not significantly different $(P>0.05)$ among treatments, protein deposition decreased slightly with the increasing protein content and thus growth appears to be affected more by dietary protein levels than by energy levels. As per NRC (1993), the optimum $\mathrm{P} / \mathrm{DE}$ values for fish range between 17 and $26 \mathrm{mg}$ protein/kJ DE which in the present study, also almost corresponds to diets with $44 \%$ protein (27.21$27.88 \mathrm{mg}$ protein $/ \mathrm{kJ} \mathrm{DE}$ ) at $26{ }^{\circ} \mathrm{C}$. Therefore, in this study, highest protein deposition with $44 \%$ dietary protein at $26^{\circ} \mathrm{C}$ may be due to balanced P/DE ratio at this level of dietary protein.

H. fossilis fed intermediate levels of dietary protein (36-44\%) exhibited higher feed intake than those fed still higher levels of protein in the diet (48-52\%). This may probably be due to the reasons that fish fed nutrient-deficient diets usually increase the feed intake to meet the protein or the energy needs. Since the diets in this study were formulated to be isoenergetic, it is plausible that the fish fed intermediate levels of dietary protein might have consumed more feed in order to meet their protein requirements.

Temperature affects the body composition by altering feed intake (Jobling 1997) and various studies have shown that body protein is significantly affected by temperature (Cui and Wootton 1988; Koskela et al. 1997; Bendiksen et al. 2003; Tidwell et al. 2003). In this study as well, in addition to dietary protein levels, temperature also had significant influence on body protein and moisture contents of fry $H$. fossilis. The carcass quality of fish in terms of carcass protein content attained its superior value for the groups fed with $44 \%$ dietary protein at $26{ }^{\circ} \mathrm{C}$ temperature. Fish fed diets containing $28-36 \%$ protein tended to deposit more fat than those fed $40,44,48$, and $52 \%$ dietary protein. In diets $\mathrm{D}_{28}, \mathrm{D}_{32}$, and $\mathrm{D}_{36}$, the carbohydrate contents increased at the expense of dietary protein which might have participated in de novo lipid synthesis from carbohydrate. Since these diets contain an improper ratio of protein to energy, this might have led to deposition of body fat from dietary carbohydrates.

Water temperature is one of the most important ecological factors that significantly influence some physiological process of fish such as growth, metabolism, and blood values. As has been shown in Table 4, hematocrit and hemoglobin concentrations were significantly $(P<$ 0.05 ) altered by different water temperatures, However, interactive effects of dietary protein and temperature were not found. The results of this study are in line of the results reported by Koeypudsa and Jongjareanjai (2010) for hybrid catfish. Data related to hematological parameters in this study indicates that to sustain normal physiological processes in the body, $H$. fossilis should be held at $26{ }^{\circ} \mathrm{C}$ water temperature.

To study the effect of water temperature on the protein requirements of fish, Daniels and Robinson (1986) conducted two independent studies in which the red drum, Sciaenops ocellatus were maintained at 22-26 ${ }^{\circ} \mathrm{C}$ water temperature in the first and at $26-33{ }^{\circ} \mathrm{C}$ in the second. According to the authors, fish reared at lower temperature required less protein (35\%) than those at higher temperature (44\%). It is considered that water temperature affects feed intake and feed conversion efficiency (NRC 1993). Therefore, it is reasonable to assume that the suboptimal temperature in the present study might have deviated the feed intake in $H$. fossilis held at $18{ }^{\circ} \mathrm{C}$ and may be one of the reasons for reduced growth performance in groups held at this temperature; even if fed with the same dietary protein level.

Water temperature has substantial effect on fish metabolism. In response to decrease in water temperature, the enzyme activity of tissues increases (Hochachka and Somero 1984). In a stressful and unfavorable environmental condition ALT and AST activities may increase in blood serum. In the present study, serum ALT and AST levels were affected by different water temperatures. Serum ALT and AST amount in different fish fed varying levels of dietary protein at 26 ${ }^{\circ} \mathrm{C}$ are comparatively lower and attained normal physiological range at requirement level (44\% dietary protein) than those fed at $18{ }^{\circ} \mathrm{C}$. These results clearly indicated that $26{ }^{\circ} \mathrm{C}$ is the favorable water temperature for better growth of $H$. fossilis fry. 
Survival rate in this study were not affected significantly by different levels of dietary protein but was more affected by temperature as the groups held at $18{ }^{\circ} \mathrm{C}$ had significant $(P<0.05)$ mortality at lowest level of dietary protein. On the other hand, mortality at $26{ }^{\circ} \mathrm{C}$ water temperature was not recoded even at the lowest level of dietary protein. The results are in line with various other finfish and shellfish studies ( $\mathrm{Li}$ et al. 2011; Sun et al. 2015; Abdelrahman et al. 2019). Azaza et al. (2008) described that the survival rate of Nile tilapia, Oreochromis niloticus was significantly lower when it was reared at lower and upper level of its optimum water temperature.

Stress resistance of the fish in different life period is affected by levels of salinity, temperature, environment, and nutrition (Jalali et al. 2008; Gholami 2010). The results of present study showed that resistance rate to thermal stress significantly higher $(P<0.05)$ in fish fed dietary protein at $26{ }^{\circ} \mathrm{C}$ water temperature who were able to withstand temperature challenge for longer duration (Table 5) than those fish fed at $18{ }^{\circ} \mathrm{C}$ water temperature which were found to be more prone to temperature challenge test and exhibited mortality in comparatively less time.

Based on the $95 \%$ maximum response of seconddegree polynomial regression analyses of $\mathrm{PD} \mathrm{g} /$ fish data, it is recommended that fry $H$. fossilis could perform well if fed with dietary protein levels between 40.8 and $41.8 \%$ with a P/DE ratio of $27.21-27.88 \mathrm{mg}$ protein/kJ DE at $26{ }^{\circ} \mathrm{C}$ water temperature. This study also corroborates that the performance of the fish and protein requirement was strictly governed by the rearing temperature as fish reared at $18{ }^{\circ} \mathrm{C}$ water temperature could not perform well in terms of growth, feed conversion, and protein deposition even if fed with the same level of dietary protein.

\section{Conclusion}

The information developed in the present study could be utilized for optimizing the growth potential of this fish by making better utilization of the nutrient at the 26 ${ }^{\circ} \mathrm{C}$, the required temperature optima. The finding of the present study would further be useful for effective management strategies for the mass culture of this highly preferred fish species.

\section{Abbreviations \\ ALT: Alanine amino transferase; AST: Aspartate amino transferase; CF: Condition factor; CP: Crude protein; DE: Digestible energy; FCR: Feed conversion ratio; GE: Gross energy; Hb: Hemoglobin; Hct: Hematocrit; HSI: Hepatosomatic index; kJ: Kilo joule; PD: Protein deposition; RBCs: Red blood cells; TGC: Thermal growth coefficient; VSI: Viscerosomatic index}

\section{Acknowledgments}

The authors are grateful to the Dean, Dr. Afaf Mohammad Babeer, Farasan University College, Jazan University, Jazan, KSA for providing necessary facilities for electronic submission of the manuscript and also for providing a highly conducive work environment. The authors are also grateful to the Head, Department of Zoology, University of Kashmir, Hazratbal, Srinagar, India for providing the laboratory facilities to carry out the experimental work and to Mr. Mufti Buhran, University Chief Executive Engineer for helping the construction of new Feed Technology Laboratory (WetLaboratory) in the Department of Zoology. Thanks are also due to Prof. Dr. Nazni Peer Khan, Professor \& Head, Department of Nutrition \& Dietetics,

Periyar University, Salem, TN, India for data analyses with two-way ANOVA.

\section{Authors' contributions}

SFS has conducted the experiments, data analyses and manuscript writing and IA has provided the laboratory facilities for feeding trials and sample analyses. He has also contributed in revision of the final manuscript. All authors read and approved the final manuscript.

\section{Funding}

This study was not funded by any Government or Private sources.

\section{Availability of data and materials}

All datasets generated during and/or analyzed during the current study are available from the corresponding author on reasonable request.

\section{Ethics approval}

Experimental protocols followed the guidelines of the Animal Care and Use Committee of Central University of Kashmir, J\&K, India.

\section{Consent for publication}

Not applicable.

\section{Competing interests}

The authors declare that they have no competing interests.

\section{Author details}

'Department of Nursing, Farasan University College, Farasan, Jazan University, Jizan, Kingdom of Saudi Arabia. ${ }^{2}$ Department of Zoology, University of Kahsmir, Hazratbal, Srinagar, Jammu and Kashmir 190006, India.

Received: 12 September 2019 Accepted: 6 January 2020

Published online: 23 January 2020

\section{References}

Abdelrahman HA, Abebe A, Boyd CE. Influence of variation in water temperature on survival, growth and yield of Pacific white shrimp Litopenaeus vannamei in inland ponds for low-salinity culture. Aquac Res. 2019;50(2):658-72.

Ahmed I. Dietary amino acid L-threonine requirements of fingerling Indian catfish, Heteropneustes fossilis (Bloch) estimated by growth and biochemical parameters. Aquacult Intl. 2007;15:337-50.

Ahmed I. Response to the ration levels on growth, body composition, energy, and protein maintenance requirement of the Indian catfish (Heteropneustes fossilis-Bloch 1974). Fish Physiol Biochem. 2010;36:1133-43.

Ahmed I. Dietary amino acid L-tryptophan requirement of fingerling Indian catfish, Heteropneustes fossilis (Bloch), estimated by growth and haematobiochemical parameters. Fish Physiol Biochem. 2012;38:1195-209.

Ahmed I. Dietary amino acid L-histidine requirement of fingerling Indian catfish, Heteropneustes fossilis (Bloch), estimated by growth and whole body protein and fat composition. J Appl Ichthyol. 2013a;29:602-9.

Ahmed I. Dietary arginine requirement of fingerling Indian catfish (Heteropneustes fossilis, Bloch). Aquacult Intl. 2013b;21:255-71.

Ahmed I. Dietary amino acid L-methionine requirement of fingerling Indian catfish, Heteropneustes fossilis (Bloch-1974) estimated by growth and haemato-biochemical parameters. Aquacult Res. 2014;45:243-58.

Ahmed I. Effects of dietary amino acid L-lysine on survival, growth and haematobiochemical parameters in Indian catfish, Heteropneustes fossilis (Bloch-1974) fingerling. J Appl Ichthyol. 2017;33:1027-33.

Ahmed I, Maqbool A. Effects of dietary protein levels on the growth, feed utilization and haemato-biochemical parameters of freshwater fish, Cyprinus Carpio Var Specularis. Fish Aqua J. 2017;8:1-12. https://doi.org/10.4172/21503508.1000187.

Akand AM, Hasan MR, Habib MBA. Utilization of carbohydrate and lapis as dietary energy source by stinging catfish, Heteropneustes fossilis (Bloch). In: De Silva SS, editor. Fish nutrition research in Asia. Proceedings of the fourth Asian fish 
nutrition workshop. Manila: Asian Fisheries Society special publication, Asian Fishery Society; 1991. p. 93-100.

Alok D, Krishnan T, Talwar GP, Garg LC. Induced spawning of catfish, Heteropneustes fossilis (Bloch), using D-Lys ${ }^{6}$ salmon gonadotropin-releasing hormone analog. Aquaculture. 1993;115:159-67. https://doi.org/10.1016/ 0044-8486(93)90366-7.

Anelli LC, Olle CD, Costa MJ, Rantin FT, Kalinin AL. Effects of temperature and calcium availability on ventricular myocardium from the neotropical teleost Piaractus mesopotamicus (Holmberg 1887-Teleostei, Serrasalmidae). J Ther Biol. 2004;29:103-13. https://doi.org/10.1016/j. jtherbio.2003.12.001.

Anwar MF, Jafri AK. Preliminary observations on growth, food conversion body composition of catfish, Heteropneustes fossilis Bloch, fed varying levels of dietary lipids. J Inland Fish Soc India. 1992;24(2):45-9.

AOAC. Official methods of analysis of the association of official analytical chemist. 16th ed. Arlington: AOAC; 1995.

APHA. Standard methods for the examination of water and wastewater. 18th, Washington DC; 1992. p. 1268.

Azaza MS, Dhraief MN, Kraïem MM. Effects of water temperature on growth and sex ratio of juvenile Nile Tilapia Oreochromis niloticus (Linneaus) reared in geothermal waters in southern Tunisia. J Thermal Biol. 2008;33(2):98-105.

Bailey J, Alanara A. Effect of feed portion size on growth of rainbow trout, Oncorhynchus mykiss (Walbaum) reared at different temperatures. Aquaculture. 2006;253:728-30.

Baker DH. Problems and pitfalls in animal experiments designed to establish dietary requirements for essential nutrients. J. Nutr. 1986;116:2339-49 https://doi.org/10.1093/jn/116.12.2339.

Bendiksen EA, Berg A, Jobling M, Arnesen AM, Masoval K. Digestibility, growth and nutrient utilization of Atlantic salmon parr (Salmo salar L.) in relation to temperature, feed fat content and oil source. Aquaculture. 2003;224:283-99.

Bever KN, Chenoweth M, Dunn A. Amino acid gluconeogenesis and glucose turnover in kelp bass (Paralabrax sp.). Am J Physiol. 1981;240(3):246-52 https://doi.org/10.1152/ajpregu.1981.240.3.R246.

Bhikajee M, Gobin P. Effect of temperature on the feeding rate and growth of a red tilapia hybrid. In: Proceedings from the $4^{\text {th }}$ International Symposium on Tilapia Aquaculture, vol. 1; 1998. p. 131-40.

Brett JR. Environmental factors and growth. In: Hoar WS, Randall DJ, Brett JR, editors. Fish Physiology, Vol 8. New York: Academic Press; 1979. p. 599-675.

Brown JA, Pepin P, Methven DA, Somerton DC. The feeding, growth and behaviour of juvenile cod, Gadus morhua, in cold environments. J Fish Biol. 1989;35:373-80. https://doi.org/10.1111/j.1095-8649.1989.tb02989.x.

Burgess WE. An atlas of freshwater and marine catfishes: a preliminary survey of the Siluriformes. Neptune City: T.F.H. Publications; 1989.

Castille FJ Jr, Lawrence AL. The effect of salinity on the osmotic, sodium and chloride concentrations in the hemolymph of euryhaline shrimp of the genus Penaeus. Comp Biochem Physiol. 1981;68A:75-80 https://doi.org/10.1016/0300-9629 (81) 90320-0.

Chatterjee N, Pal AK, Manush SM, Das T, Mukherjee SG. Thermal tolerance and oxygen consumption of Labeo rohita and Cyprinus carpio early fingerlings acclimated to three different temperatures. J Therm Biol. 2004;29:265-70 https://doi.org/10.1016/j.jtherbio.2004.05.001.

Christopher JSG, Murugesan AG, Sukumaran N. Induction of meiotic gynogenesis in the stinging catfish Heteropneustes fossilis (Bloch) and evidence for female homogamety. Aquac Res. 2010;42:129-38. https://doi.org/10.1111/j.13652109.2010.02593.x.

Cowey CB. Protein and amino acid requirements of finfish. In: J. E. Halver and K. Tiews (Ed), Finfish Nutrition and fishfeed technology. 1979;: :3-16. Heenemann, Berlin.

Cui Y, Wootton RJ. Effects of ration, temperature and body size on the body composition and energy content of the minnow, Phoxinus phoxinus (L.). J Fish Biol. 1988;32:749-64. https://doi.org/10.1111/j.1095-8649.1988.tb05414.x.

Daniels WH, Robinson EH. Protein and energy requirements of juvenile red drum (Sciaenops ocellatus). Aquaculture. 1986;73:243-52 https://doi.org/10.1016/ 0044-8486(86)90354-6.

Davis AT, Stickney RR. Growth responses of Tilapia aurea to dietary protein quality and quantity. Tran American Fish Soc. 1978;107:479-83.

Dehadrai PV, Yusuf KM, Das RK. Package and practices for increasing production of air breathing fishes. In: Aquaculture Extension Manual, New Series, Information and Extension Division of CIFRI: Indian Council of Agriculture Research; 1985. p. 1-14.
Dias J, Huelvan C, Dinis MT, Metaliller R. Influence of dietary bulk agents (silica, cellulose and a natural zeolite) on protein digestibility, growth, feed intake and feed transit time in European seabass (Dicentrarchus labrax) juveniles. Aquat Liv Resur. 1998;11:219-26. https://doi.org/10.1016/S09907440(98)89004-9.

Duan Q, Mai K, Zhong H, Si L, Wang X. Studies on the nutrition of the large yellow croaker, Pseudosciaena crocea R: 1 . Growth response to graded levels of dietary protein and lipid. Aquac Res. 2001;32:46-52. https://doi.org/10. 1046/j.1355-557x.2001.00048.x.

Duncan DB. Multiple range and multiple 'F' tests. Biometrics. 1955;11:1-42.

Dutta H. Pisces: Growth in Fishes. Gerontol. 1994;40:97-112 https://doi.org/10. 1159/000213581.

El-Dakar AY, Shalaby SM, Saoud IP. Dietary protein requirement of juvenile marbled spinefoot rabbitfish Siganus rivulatus. Aquac Res. 2011;42:1050-5. https://doi.org/10.1111/j.1365-2109.2010.02694.x.

El-Sayed AFM, El-Ghobashy A, Al-Amoudi M. Effects of pond depth and water temperature on the growth, mortality and body composition of Nile tilapia, Oreochromis niloticus (L.). Aquac Res. 1996;27:681-7. https://doi.org/10.1046/j. 1365-2109.1996.00776.x

Farhat KMA. Growth, feed conversion, and nutrient retention efficiencies of African catfish, Clarias gariepinus (Burchell) fingerling fed diets with varying levels of protein. J Appl Aquacult. 2011;23:304-16 https://doi.org/10.1080/ 10454438.2011.626370.

Farhat, Khan MA. Effects of dietary arginine levels on growth, feed conversion, protein productive value and carcass composition of stinging catfish fingerling Heteropneustes fossilis (Bloch). Aquacult Intl. 2012; 20, 935-950 DOI https://doi.org/10.1007/sl0499-0l2-9519-3.

Farhat KMA. Effects of varying levels of dietary L-histidine on growth, feed conversion, protein gain, histidine retention, hematological and body composition in fingerling stinging catfish Heteropneustes fossilis (Bloch). Aquaculture. 2013a;404-405:130-8. https://doi.org/10.1015/j.aquaculture.2013. 04.020.

Farhat KMA. Dietary L-lysine requirement of fingerling stinging catfish, Heteropneustes fossilis (Bloch) for optimizing growth, feed conversion, protein and lysine deposition. Aquac Res. 2013b;44:523-33. https://doi.org/10.1111/j. 1365-2109.2011.03054.x.

Farhat KMA. Dietary L-tryptophan requirement of fingerling stinging catfish, Heteropneustes fossilis (Bloch). Aquac Res. 2014a;45:1224-35. https://doi.org/ 10.1111/are.12066.

Farhat KMA. Response of fingerling stinging catfish, Heteropneustes fossilis (Bloch) to varying levels of dietary L-leucine in relation to growth, feed conversion, protein utilization, leucine retention and blood parameters. Aquacult Nutr. 2014b;20:291-302. https://doi.org/10.1111/anu.12077.

Farhat KMA. Total sulfur amino acid requirement and cystine replacement value for fingerling stinging catfish, Heteropneustes fossilis (Bloch). Aquaculture. 2014c;426-427:270-81 https://doi.org/10.1016/j.aquaculture. 2014.02.023.

Farhat KMA. Growth, feed conversion and body composition of fingerling stinging catfish Heteropneustes fossilis (Bloch) fed varying levels of dietary L-threonine. Aquac Res. 2017;48:2355-68. https://doi.org/10. 1111/are.13071.

Firdaus S. On relative efficiency of purified diets, with variable protein levels, in young catfish Heteropneustes fossilis Bloch. Indian J Fish. 1993;40:43-6.

Firdaus S, Jafri AK. Growth and haematological response of young catfish Heteropneustes fossilis Bloch, to dietary phosphorous supplementation. J Aqua Trop. 1996;11:263-9.

Firdaus S, Jafri AK, Khan MA. Effect of dietary levels of mineral mixture on the growth, body composition and haematology of catfish, Heteropneustes fossilis Bloch. J Aqua Trop. 2002;17:273-81.

Firdaus S, Jafri AK, Rahman N. Effect of iron deficient diet on the growth and haematological characteristics of the catfish, Heteropneustes fossilis Bloch. J Aqua Trop. 1994;9:179-85.

Forster I, Hardy RW. Energy. In: Stickney RR, editor. Encyclopedia of Aquaculture. New York: Wiley; 2000. p. 292-8.

Fry FEJ. Effects of environment on animal activity. University of Toronto Studied Biology Series No. 55. Publ Ont Fish Res Lab. 1947;68:1-62.

Gholami M. Effects of n-3 HUFA enrichment Daphnia magnaon growth, survival, stress resistance and fatty acid composition of Whitefish fry (Rutilus frisii kutum). Fish. and Aquatic Sci. 2010;5(1):49-55. https://doi.org/10.3923/jfas. 2010.49.55. 
Gullu K, Guroy G, Celik I, Tekinay AA. Optimal dietary protein levels in juvenile electric blue cichlid (Sciaenochromis fryeri). Isr J Aquacult Bamid. 2008;60:2617. http://hdl.handle.net/10524/19267.

Haider G. Comparative studies of blood morphology and haemopoiesis of some teleost. Observations on cells of the red series. J Zool. 1973;179:355-83.

Halver JE. The vitamins. In: Halver JE, Hardy RW, editors. Fish nutrition. 3rd ed. San Diego: Academic Press; 2002. p. 61-141.

Halver JE, Hardy RW. In: Halver JE, Hardy RW, editors. Fish nutrition. 3rd ed. San Diego: Academic Press; 2002. p. 500

Han KN, Lee SW, Wang SY. The effect of temperature on the energy budget of the Manila clam, Ruditapes philippinarum. Aquacult Intl. 2008;16:143-52. https://doi.org/10.1007/s10499-007-9133-y.

Haniffa MA, Sridhar S. Induced spawning of the spotted murrel Channa punctatus and the catfish Heteropneustes fossilis using ovaprim and human chorionic gonadotropin (HCG). Veterinarski Archive. 2002;72:51-6 Hrčak ID: 78400 URI https://hrcak.srce.hr/78400.

Hilge V. Influence of temperature on the growth of the European catfish (Isilurus glanis). J Appl Ichthyol. 1985;1:27-31. https://doi.org/10.1111/j.1439-0426. 1985.tb00407.x.

Hochachka PW, Somero GN. Biochemical adaptation. Princeton University Press; Princeton, New Jersey: 1984; p. 525.

Huang JF, Xu QY, Chang YM. Effects of temperature and dietary protein on the growth performance and IGF-I mRNA expression of juvenile mirror carp (Cyprinus carpio). Aquacult Nutr. 2016;22:283-92.

Jalali MA, Hosseini SA, Imanpoor MR. Effect of vitamin E and highly unsaturated fatty acid enriched Artemia urmianaon growth performance, survival and stress resistance of Beluga (Huso huso) larvae. Aquacult. Res. 2008;39(12): 1286-1291. https://doi.org/10.1111/j.1365-2109.2008.01992.x.

Jhingran VG. Culture of air-breathing fishes and non-air-breathing predatory carnivorous fishes. In: Jhingran VG, editor. Fish and Fisheries of India. 3rd ed. Delhi: Hindustan Publishing Corporation; 1991. p. 498-503.

Jobling M. Temperature and growth: modulation of growth rate via temperature change. In: Wood CM, McDonald DG, editors. Global Warming: Implications for Freshwater and Marine Fish. Cambridge: Cambridge University Press; 1997. p. 225-53.

Jonassen TM, Imsland AK, Kadowaki S, Stefansson SO. Interaction of temperature and photoperiod on growth of Atlantic halibut Hippoglossus hippoglossus. L Aquac Res. 2000;31:219-27. https://doi.org/10.1046/j.1365-2109.2000.00447.x

Khan MA, Abidi SF. Optimum ration level for better growth, conversion efficiencies and body composition of fingerling Heteropneustes fossilis (Bloch). Aquacult Intl. 2010;18:175-88. https://doi.org/10.1007/s10499-008-9234-2.

Khan MA, Abidi SF. Effect of dietary L-lysine levels on growth, feed conversion, lysine retention efficiency and haematological indices of Heteropneustes fossilis (Bloch) fry. Aquacult Nutr. 2011a;17:e657-67. https://doi.org/10.1111/j. 1365-2095.2010.00815.x.

Khan MA, Abidi SF. Dietary arginine requirement of Heteropneustes (Bloch) fry based on growth, nutrient retention and hematological parameters. Aquacult Nutr. 2011b;17:418-28. https://doi.org/10.1111/j.1365-2095.2010.00819.x.

Khan MA, Abidi SF. Effect of varying protein-energy ratios on growth, nutrient retention, somatic indices and digestive enzyme activities of Singhi Heteropneustes fossilis fry (Bloch). J World Aquacult Soc. 2012;43:490-501. https://doi.org/10.1111/j.1749-7345.2012.00587.x.

Khan MA, Abidi SF. Dietary Histidine requirement of Singhi Heteropneustes fossilis (Bloch). Aquacult Res. 2014;45:1341-54. https://doi.org/10.1111/are.12081.

Khan MS, Ang KJ, Ambak MA, Saad CR. Optimum dietary protein requirement of a Malaysian freshwater catfish, Mystus nemurus. Aquaculture. 1993;112:227-35 https://doi.org/10.1016/0044-8486(93)90448-8.

Kim JD, Lall SP, Milley JE. Dietary protein requirements of juvenile haddock (Melanogrammus aeglefinus L.). Aquacult Res. 2001;32:1-7. https://doi.org/10. 1046/j.1355-557x.2001.00001.x.

Kim SS, Lee KJ. Dietary protein requirement of juvenile tiger puffer (Takifugu rubripes). Aquaculture. 2009;287:219-22 https://doi.org/10.1016/j.aquaculture. 2008.10.021.

Koeypudsa W, Jongjareanjai M. Effect of water temperature on hematology and virulence of Aeromonas hydrophila in hybrid catfish (Clarias gariepinus Burchell X C. macrocephalus Gunther). Thai J Med. 2010;40: 179-86.

Koskela JJ, Pirhonen J, Jobling M. Feed intake, growth rate and body composition of juvenile Baltic salmon exposed to different constant temperatures. Aquacult Intl. 1997;5:351-60. https://doi.org/10.1023/A: 1018316224253.
Kumar D, Marimuthu K, Haniffa MA, Sethuramalingam TA. Optimum dietary protein requirement of striped murrel Channa striatus fry. Malaysian J Sci. 2010;29:52-61.

Kumar R. Ammonia stress on transaminases level in brain of an air-breathing teleost Channa punctatus (Bloch). Adv Biol. 1999;18:53-60.

Larsson S, Berglund I. The effect of temperature on the growth energetic, growth efficiency of Aractic charr (Salvelinus alpinus L.) from four Swedish populations. J Ther Biol. 2005;30:29-36 https://doi.org/10.1016/j.jtherbio.2004. 06.001 .

Lee HYM, Cho KC, Lee JE, Yang SG. Dietary protein requirement of juvenile giant croaker, Nibea japonica Temminck and Schlegel. Aquac Res. 2001;32:112-8. https://doi.org/10.1046/j.1365-2095.2003.00255.x.

Lee JK, Cho SH, Park SU, Kim KD, Lee SM. Dietary protein requirement for young turbot (Scophthalmus maximus L.). Aquacult Nutr. 2003;9:283-6. https://doi. org/10.1046/j.1365-2095.2003.00255.x.

Li Y, Sun G, Liu Y, Gao T, Yu K, Liu J. Effects of temperature on feed intake, growth and digestive enzyme activity of turbot Scophthalmus maximus $\mathrm{L}$. in high stocking density of closed recirculation aquaculture system. Prog Fish Sci. 2011;32:17-24.

Lupatsch I, Kissil GW, Sklan D, Pfeffer E. Effects of varying dietary protein and energy supply on growth, body composition and protein utilization in gilthead seabream (Sparus aurata L.). Aquacult. Nutr. 2001;7:71-80. https:// doi.org/10.1046/j.1365-2095.2001.00150.x.

Mishra BM, Khalid MA, Labh SN. Assessment of the effect of water temperature on length gain, feed conversion ratio (FCR) and protein profile in brain of Labeo rohita (Hamilton 1822) fed Nigella sativa incorporated diets. Intl J Fish Aquatic Studies. 2019;7(3):06-13.

Mohamed SJ. Dietary pyridoxine requirement of the Indian catfish Heteropneustes fossilis. Aquaculture. 2001;194:327-35 https://doi.org/10.1016/S00448486(00)00510-X

Mohamed SJ, Ibrahim A. Quantifying the dietary niacin requirement of the Indian catfish, Heteropneustes fossilis (Bloch) fingerlings. Aquac Res. 2001;32:157-62. https://doi.org/10.1046/j.1365-2109.2001.00530.x.

Ng WK, Soon SC, Hashim R. The dietary protein requirement of a bagrid catfish, Mystus nemurus (Cuvier and Valenciennes), determined using semi purified diets of varying protein level. Aquacult Nutr. 2001;7:45-51. https://doi.org/10. 1046/j.1365-2095.2001.00160.x

Niamat R, Jafri AK. Growth response of the siluroid, Heteropneustes fossilis Bloch, fed pelleted feed. Aquaculture. 1984;37:223-9 https://doi.org/10.1016/00448486(84)90155-8

NRC. Nutrient Requirements of Fish. Nutrient requirements of domestic animals. Washington, DC: Committee on Animal Nutrition, Board on Agriculture, National Research Council, National Academy Press; 1993. p. 114.

Otterle IE, Folkvord A, Moller D. Effects of temperature and density on growth, survival and cannibalism of juvenile cod (Gadus morhua). ICES Marine Sci Symp. 1994;198:632-6.

Oyugi D, Cucherousset J, Ntiba JM, Kisia SM, Harper DM, Britton JR. Life history traits of an equatorial carp Cyprinus carpio population in relation to thermal influences on invasive populations. Fish Res. 2011;110:92-7.

Ozorio ROA, Valente LMP, Correia S, Pousao-Ferreira P, Damasceno-Oliveira D, Escorcio C, Oliva-Teles A. Protein requirement for maintenance and maximum growth of two-banded sea bream (Diplodus vulgaris) juveniles. Aquacult Nutr. 2006;15:85-93. https://doi.org/10.1111/j.1365-2095.2008.00570.x.

Peres $\mathrm{H}$, Oliva-Teles A. Influence of temperature on protein utilization in juvenile European seabass (Dicentrarchus labrax). Aquaculture. 1999;170:337-48 https://doi.org/10.1016/S0044-8486(98)00422-0.

Pillay TVR. Nutrition and Feeds. In: Aquaculture principles and practices. London: Fishing News Books; 1990. p. 92-155.

Rahman MA, Gheyasuddin H, Rasid MH, Choudhury MFZ. Proximate composition and native quality of freshwater Zeol fishes of Bangladesh. Bangladesh J Fisher. 1982;2-5:37-43.

Reitman S, Frankel S. A Colorimetric method for the determination of serum glutamic oxalacetic and glutamic pyruvic transaminases. Am J Clinical Pathol. 1957;28:56-63.

Saha KC, Guha BC. Nutritional investigation on Bengal fish. Indian J Med Res. 1939;26:921-7 ISSN: 0019-5359.

Sarma K, Pal AK, Ayyapan S, Das T, Manush SM, Debnath D, Baruah K. Acclimation of Anabas tetudineus (Bloch) to three test temperatures influences thermal tolerance and oxygen consumption. Fish Physiol Biochem. 2010;36:85-90. https://doi.org/10.1007/s10695-008-9293-3. 
Shcherbina MA, Kazlauskene OP. Water temperature and digestibility of nutrient substances by carp. Hydrobiologia. 1971;9:40-4.

Shimeno S, Hosokawa H, Takeda M, Kajiyama H. Effects of calorie to protein ratios in formulated diet on the growth, feed conversion and body composition of young yellowtail. Bull Jpn Soc Sci Fish. 1980;46:1083-7.

Siddiqui TQ, Khan MA. Effects of dietary protein levels on growth, feed utilization, protein retention efficiency and body composition of young Heteropneustes fossilis (Bloch). Fish Physiol Biochem. 2009;35:479-88. https://doi.org/10.1007/ s10695-008-9273-7.

Singh RK, Chavan SL, Desai AS, Khandagale PA. Influence of dietary protein levels and water temperature on growth, body composition and nutrient utilization of Cirrhinus mrigala (Hamilton 1822) fry. J Therm Biol. 2008;33:20-6 https://doi.org/10.1016/j.jtherbio.2007.09.003.

Singh RK, Chavan SL, Desai AS, Khandagale PA. Effect of water temperature on dietary protein requirement, growth and body composition of Asian catfish, Clarias batrachus fry. J Therm Biol. 2009;34:8-13 https://doi.org/10.1016/j. jtherbio.2008.08.005.

Snedecor GW, Cochran WG. Statistical Methods. 6th ed. Ames: Iowa State Univ. Press; 1982. p. 593

Steffens W. Protein utilization of rainbow trout (Salmo gairdneri) and carp (Cyprinus carpio): a brief review. Aquaculture. 1981;23:337-45 https://doi.org/ 10.1016/0044-8486(81)90026-0.

Steinhagen D, Kruse P, Korting W. Some haematological observations on Carp Cyprinus carpio L. experimentally infected with Trypanoplasma borelli Laveran and Mesnil. 1901 (Protozoa: Kitenoplastida). J Fish Dis. 1990;14:157-62. https:// doi.org/10.1111/j.1365-2761.1990.tb00768.X.

Sun Z, Xia S, Feng S, Zhang Z, Rahman MM, Rajkumar M, Jiang S. Effects of water temperature on survival, growth, digestive enzyme activities, and body composition of the leopard coral grouper Plectropomus leopardus. Fish Sci. 2015;81:107-12. https://doi.org/10.1007/s12562-014-0832-9.

Tacon AGJ, Cowey CB. Protein and amino acid requirements. In: Tytler P, Calow P, editors. Fish Energetics: new perspectives. Baltimore: The John Hopkins University Press; 1985. p. 155-83.

Thakur NK. Possibilities and problems of catfish culture in India. J Inland Fish Soc. India. 1991;23:80-90.

Tharakan B, Joy KP. Effects of mammalian gonadotropin-releasing hormone analogue, Pimozide, and the combination on plasma gonadotropin levels in different seasons and induction of ovulation in female catfish. J Fish Biol. 1996;48:623-32. https://doi.org/10.1111/j.1095-8649.1996.tb01457.x.

Tibbetts SM, Lall SP, Milley JE. Effects of dietary protein and lipid levels and DP/ DE ratio on growth, feed utilization and hepatosomatic index of juvenile haddock, Melanogrammus aeglefinus L. Aquacult Nutr. 2005;11:67-75. https://doi.org/10.1111/j.1365-2095.2004.00326.x.

Tidwell JH, Coyle SD, Bright LA, Van Arnum A, Yasharian D. Effects of water temperature on growth, survival, and biochemical composition of largemouth bass Micropterus salmonides. J World Aquacult Soc. 2003;34:17583. https://doi.org/10.1111/j.1749-7345.2003.tb00054.x.

Turker A. Effect of photoperiod on growth of trout (Oncorhynchus mykiss) in cold ambient sea water. Israel J Aquac (Bamidgeh). 2009;61:57-62.

Usmani N, Jafri AK. Effect of fish size and temperature on the utilization of different protein source in two catfish species. Aquac Res. 2002;33:959-67. https://doi.org/10.1046/j.1365-2109.2002.00747.x.

Usmani N, Jafri AK, Khan MA. Nutrient digestibility studies in Heteropneustes fossilis (Bloch), Clarias batrachus (Linnaeus) and C. gariepinus (Burchell). Aquac Res. 2003:34:1247-53. https://doi.org/10.1046/j.1365-2109.2003.00930.x.

Van Ham EH, Berntssen MHG, Imsland AK, Parpoura AC, Bonga SEW, Stefansson SO. The influence of temperature and ration on growth, feed conversion, body composition and nutrient retention of juvenile turbot (Scophthalmus maximus). Aquaculture. 2003;217:547-58 https://doi.org/10.1016/S00448486(02)00411-8

Vijayakumar C, Sridhar S, Haniffa MA. Low cost breeding and hatching techniques for the catfish Heteropneustes fossilis for small-scale farmers. NAGA. 1998;21:15-7.

Wang Y, Guo J, Li K, Bureau DP. Effects of dietary protein and energy levels on growth, feed utilization and body composition of cuneate drum (Nibea miichthioides). Aquaculture. 2006;252:421-8 https://doi.org/10.1016/j. aquaculture.2005.06.051.

Wedemeyer GR, Meyer FP, Smith L. Environmental Stress and Fish Diseases. Delhi: Narendra Publishing House; 1999. p. 107.

Wong, SY. Colorimetric determination of iron and hemoglobin in blood. II J. Biol. Chem. 1928;77:409-412.
Xia J, Li X. Effect of temperature on blood parameters of the salamander Batrachupems tibetanus (Schmidt, 1925) (Amphibia: Hynobiidae). Russian J Ecol. 2010;41(1):102-6. https://doi.org/10.1134/S1067413610010194.

Yokoyama HO. Studies on the origin, development and seasonal variations in the blood cells of the perch, Perca J. Eavescens. Ph.D. Thesis. Univ. Wisconsin, Madison, Wis. 144 pp, 1974.

Zehra S, Khan MA. Dietary protein requirement for fingerling Channa punctatus (Bloch), based on growth, feed conversion, protein retention and biochemical composition. Aquacult. Intl. 2012;20:383-95. https://doi.org/10.1007/s10499-011-9470-8.

Zeitoun $I H$, Ullrey DE, Magee WT, Gill JL, Bergen WG. Quantifying nutrient requirements of fish. J Fisher Res Board Canada. 1976;33:167-72 https://doi.org/10.1139/f76-019.

\section{Publisher's Note}

Springer Nature remains neutral with regard to jurisdictional claims in published maps and institutional affiliations.

\section{Ready to submit your research? Choose BMC and benefit from:}

- fast, convenient online submission

- thorough peer review by experienced researchers in your field

- rapid publication on acceptance

- support for research data, including large and complex data types

- gold Open Access which fosters wider collaboration and increased citations

- maximum visibility for your research: over $100 \mathrm{M}$ website views per year

At BMC, research is always in progress.

Learn more biomedcentral.com/submissions 